Research Article

\title{
Development of a Daily Databank of Solar Radiation Components for Moroccan Territory
}

\author{
Mohammed Benchrifa $\mathbb{D}^{1}{ }^{1}$ Hajar Essalhi, ${ }^{1}$ Rachid Tadili, ${ }^{1}$ Mohammed N. Bargach, ${ }^{1}$ \\ and Abdellah Mechaqrane ${ }^{2}$ \\ ${ }^{1}$ Mohammed V University of Rabat, Faculty of Science, B. P 1014 Rabat, Morocco \\ ${ }^{2}$ Sidi Mohamed Ben Abdellah University, Faculty of Science and Technology, B. P, Fez, Morocco \\ Correspondence should be addressed to Mohammed Benchrifa; simobenchrifa@gmail.com
}

Received 6 December 2018; Revised 4 March 2019; Accepted 26 March 2019; Published 16 May 2019

Guest Editor: Angel A. Bayod-Rújula

Copyright (C) 2019 Mohammed Benchrifa et al. This is an open access article distributed under the Creative Commons Attribution License, which permits unrestricted use, distribution, and reproduction in any medium, provided the original work is properly cited.

\begin{abstract}
The main objective of this work is to create a daily updated database that includes all components of solar radiation, either energetic or spectral radiation. This will lead us to quantify the Moroccan solar potential and to determine the dimensions of all types of solar thermal and photovoltaic systems. Consequently, the obtained database will be the fundamental support for engineers, designers, and all organizations interested in developing solar systems, in different regions throughout Morocco. It will also be a basic tool for researchers in modelling and simulating the new solar systems. Firstly, we used one year's worth of measurements of the different components of the solar radiation, provided by the National Meteorological Department, to establish the extrapolation equations between the global radiation at the reference site and the global radiation of twenty-eight other sites. As well as with the same measurements, we developed the correlation equations between the global solar radiation and the other solar radiation components. Secondly, from ten years of Fez station's daily global radiation measurements and through the extrapolation equations, we were able to estimate the global radiation of all Moroccan cities. Then, by using the obtained global radiation data and the correlation equations, we predicted the other components of solar radiation. Subsequently, with a new measurement campaign carried out on several sites, we validated the estimation models by using the usual statistical indicators. In addition, we compared our results with those obtained by other estimation models. The resulting differences for each solar component display the advantage of our model with errors under $6 \%$. To facilitate the use of our results, we compiled them into maps representing the spread of solar radiation across Morocco.
\end{abstract}

\section{Introduction}

The various applications of solar energy developed in recent years have increased the need for solar radiation component data. However, in most cases, there are not enough stations covering the entire country, and the existing stations do not measure all energetic and spectral components of solar radiation.

To remedy this problem, several works using different prediction models have been developed to estimate these solar components around the world. Among these models, we can cite physical models, empirical models [1-3], artificial neural network models [4-7], hybrid models using a combination of several methods $[8,9]$, and the models based on the satellite images data $[10,11]$. Thus, the physical models are based on physical parameters, which estimates the global radiation from insolation duration $[12,13]$, meteorological variables $[14,15]$, and spatial variables [16] in different sky conditions $[17,18]$. Also, this model predicts the diffuse solar radiation [19] from the global radiation [20], the insolation duration [21], or the clarity index $[22,23]$ in different climatic zones [21] and in different sky conditions [24, 25]. However, the same parameters have been used to predict the direct [26], inclined [27] solar radiation and spectral solar components $[28,29]$. 
TABLE 1: Linear models for estimating daily global solar radiation.

\begin{tabular}{lccc}
\hline Estimation models & Equations & $R$ & Regions \\
\hline Lemmini's model [32] & $K_{t}=0.25+0.49 \sigma$ & 0.92 & Beni-Mellal, Morocco \\
Bargach's model [31] & $K_{t}=0.27+0.5 \sigma$ & 0.9 & Rabat, Morocco \\
Nfaoui's model [33] & $K_{t}=0.26+0.52 \sigma$ & 0.93 & Rabat, Morocco \\
Zou et al.'s model [7] & $K_{t}=0.208+0.559 \sigma$ & 0.91 & Tengchong, China \\
\hline
\end{tabular}

TABLE 2: Quadratic and cubic models for estimating daily global solar radiation.

\begin{tabular}{lccc}
\hline Estimation models & Equations & $R$ & Region \\
\hline Ben Kaddour's model [34] & $K_{t}=0.18+0.83 \sigma-0.31 \sigma^{2}$ & 0.93 & Casablanca, Morocco \\
Zou et al.'s model [7] & $K_{t}=0.185+0.587 \sigma+0.037 \sigma^{2}-0.032 \sigma^{3}$ & 0.93 & Aletai, China \\
\hline
\end{tabular}

This work aims at establishing a solar data bank of energetic components $\left(H_{j}, H_{b j}, H_{d j}\right.$, and $\left.H_{\beta j}\right)$ and spectral components ( $H_{\mathrm{UVT}}, H_{\mathrm{PAR}}$, and $H_{\mathrm{IR}}$ ) all over Morocco. However, this work will be completed in two main steps as follows:

(i) First step: we will establish the extrapolation equations to estimate the global solar radiation. Then, we will develop the correlation equations to estimate the other solar radiation components

(ii) Second step: we will use the obtained extrapolation equations to generate the global solar radiation for twenty-eight sites from reference station data. Then, we will bring together the correlation equations and the estimated global radiation to generate the solar energetic and solar spectral component

The obtained results will be subject to a validity test, by comparing them with the measurements collected in available stations. In addition, we will compare our results with those obtained by other estimation models [7, 30-34].

Finally, all results will be presented in maps [35-38] showing all over Morocco.

\section{Review of Solar Component Estimation Models}

All solar energy conversion systems require knowledge of the solar radiation component measurements. However, in most cases, these measures are not available. For this reason, several studies have been carried out for estimating the components of solar radiation from different variables such as the duration of insolation, the fraction of insolation, and the coefficient of clarity.

2.1. Global Solar Radiation Estimation Models. The simplest model for estimating solar radiation is the linear model developed by Angstrom and after revised by Prescott. This model establishes a direct relationship between the global solar radiation and the insolation fraction [39].

The Angstrom-Prescott model is as follows:

$$
K_{t}=a+b \sigma,
$$

where $a$ and $b$ are empirically determined regression constants.

Based on the linear model, several studies have been performed to predict global solar radiation. Among these models, we can cite the models in Table 1.

Other models have been developed such as the quadratic model and cubic model. Among these models, we can mention the models in Table 2.

2.2. Diffuse Solar Radiation Estimation Models. The value of diffuse solar radiation constitute an important data in the study of solar conversion systems. However, several works have focused on the prediction of this component and this by using different variables such as the clarity index $K_{t}$. Among these works, we found the following:

(i) Ben Kaddour's model [34]

$$
K_{d}=0.961+0.456 K_{t}-3.344 K_{t}^{2}+1.67 K_{t}^{3}
$$

(ii) Nfaoui's model [33]

$$
\begin{aligned}
& K_{d}= \begin{cases}0.98, & K_{t}<0.1, \\
-1.48 K_{t}^{2}+0.15 k_{t}+0.98, & K_{t} \geq 0.1\end{cases} \\
& R=0.93
\end{aligned}
$$

(iii) Wang et al.'s model, Injinagaui, China [25]

$$
\begin{aligned}
K_{d}= & 14.7924 K_{t}^{4}-23.95 K_{t}^{3}+11.1612 K_{t}^{2} \\
& -2.4767 K_{t}+1.1665 \\
R= & 0.88
\end{aligned}
$$

\section{Data Description}

3.1. Used Data. The Laboratory of Solar Energy and the Environment (LESE) of Mohammed V University of Rabat, Morocco, has, since 2008, a network of five 
TABle 3: The geographical data of the measuring stations' locations [40].

\begin{tabular}{|c|c|c|c|}
\hline Measuring station & Latitude $\left({ }^{\circ}\right) \Phi$ & Longitude $\left({ }^{\circ}\right) \lambda$ & Altitude (m) \\
\hline Agadir & 30.38 & -9.57 & 18 \\
\hline Al-Hoceima & 35.18 & -3.83 & 12 \\
\hline Beni-Mellal & 32.37 & -6.4 & 468 \\
\hline Bouarfa & 32.52 & -1.95 & 1100 \\
\hline Casa & 33.57 & -7.67 & 56 \\
\hline Dakhla & 23.77 & -15.93 & 10 \\
\hline El Jadida & 33.23 & -8.52 & 27 \\
\hline Essaouira & 31.52 & -9.78 & 7 \\
\hline Ifran & 33.5 & -5.17 & 1663 \\
\hline Kenitra & 34.3 & -6.6 & 5 \\
\hline Laayoun & 27.17 & -13.22 & 63 \\
\hline Larache & 35.18 & -6.13 & 46 \\
\hline Marrakech & 31.62 & -8.03 & 463 \\
\hline Meknes & 33.88 & -5.53 & 548 \\
\hline Midelt & 32.68 & -4.73 & 1508 \\
\hline Nador & 35.15 & -2.92 & 7 \\
\hline Nousar & 33.37 & -7.57 & 200 \\
\hline Ouarzazate & 30.93 & -6.9 & 1136 \\
\hline Oujda & 34.78 & -1.93 & 465 \\
\hline Errachidia & 31.93 & -4.4 & 1037 \\
\hline Safi & 32.28 & -9.23 & 43 \\
\hline Sidi Ifni & 29.37 & -10.18 & 49 \\
\hline Sidi Sliman & 34.23 & -6.05 & 51 \\
\hline Tangier & 35.72 & -5.75 & 15 \\
\hline Tantan & 28.6 & -11.08 & 229 \\
\hline Taza & 34.22 & -4 & 509 \\
\hline Tetouan & 35.57 & -5.33 & 5 \\
\hline Rabat & 34 & -6.83 & 75 \\
\hline
\end{tabular}

measuring stations installed in Rabat, Fez, Tangier, Tetouan, and Marrakech. These stations measure all components of solar radiation and climatic variables such as the following:

(i) Energy components: global, diffuse, and direct solar radiation, as well as the overall inclined plane

(ii) Spectral components: ultraviolet, infrared, and synthetically active light solar radiation

(iii) Climatic variables: ambient temperature, relative humidity, wind speed, wind direction, and precipitation

In addition to these measures, the National Meteorological Department has made available to us one year of climatic variables and solar component measurements for 29 stations of the national network.

Table 3 represents the geographical data of the measuring stations' locations.
3.2. Acquisition of Data. For each station, the following instruments record the measurements of the different components of the solar radiation [41]:

(i) The Kipp \& Zonen brand SP-Lite pyranometer for global solar radiation measurements $(2 \%$ accuracy). The same type of instrument was used to measure the diffuse radiation, but with a sun visor strip to hide the direct radiation

(ii) Pyrheliometer mounted on a follower type Eppley model NIP 31820 E6 to measure direct solar radiation (accuracy 0.5\%)

(iii) Total Ultraviolet Radiometer (TUVR) model, type Eppley for measuring the total solar ultraviolet radiation (accuracy 2\%)

(iv) Radiometer model NIP 31820 E6, type Eppley, for the measurement of radiation infrared (precision $0.5 \%$ )

(v) Quantum sensor SKP215, type Campbell Scientific for the measurement of photosynthetically active radiation PAR (accuracy 0.5\%)

(vi) Anemometer equipped with a wind vane model wind monitor 05103, type Campbell Scientific, for the measurement of wind speed and direction (accuracy $0.25 \%$ )

(vii) Temperature and relative Humidity Probe HMP45C, manufactured for Campbell Scientific by Vaisala (temperature accuracy $0.2 \%$, humidity accuracy $1 \%$ )

(viii) Rain Gauge ARG100, manufactured by Environmental Measurements for Campbell Scientific, to measure precipitation (accuracy $4 \%$ )

3.3. Storing Data. All instruments mentioned before are connected to a data acquisition unit (CR10X) with a storage module. Using a computer program, we integrate the measurements collected every 5 seconds over an hour. The obtained hourly values are stored in the raw data files. Then the raw data files are processed and tested to detect and eliminate erroneous values and replace some missing values. In the end, the hourly values are integrated to obtain the daily values.

3.4. Characteristics and Description of the Reference Site. The Fez station has been selected as a reference site because of its central geographical location. This city is known as the cultural capital of Morocco $\left(33^{\circ} 56^{\prime} \mathrm{N}\right.$, Longitude $4^{\circ} 99^{\prime} \mathrm{W}$, elevation $579 \mathrm{~m}$ ) characterized by a seasonal climate, cold and rainy during winter, dry and warm during summer, and mild during spring and autumn [42].

The radiometric station was placed at the top of the Faculty of Science and Technology of Fez's building. The site of the station is completely clear of any shadow effect.

Statistical analysis of this station's data shows a very small percentage of missing or erroneous data (15 erroneous or 
TABLE 4: The equations used for the global radiation extrapolation in Morocco.

\begin{tabular}{|c|c|c|c|}
\hline Site & $a_{\text {site }}$ & $b_{\text {site }}$ & $R^{2}$ \\
\hline Agadir & 0.79 & 994 & 0.89 \\
\hline Al-Hoceima & 0.94 & -181 & 0.85 \\
\hline Beni-Mellal & 0.94 & 409 & 0.8 \\
\hline Bouarfa & 0.81 & 780 & 0.8 \\
\hline Casa & 0.91 & 322 & 0.82 \\
\hline Dakhla & 0.7 & 1907 & 0.84 \\
\hline El Jadida & 0.95 & 50 & 0.89 \\
\hline Essaouira & 0.89 & 539 & 0.83 \\
\hline Ifran & 0.97 & -52 & 0.83 \\
\hline Kenitra & 0.97 & -15 & 0.83 \\
\hline Laayoun & 0.8 & 1285 & 0.85 \\
\hline Larache & 1.01 & -383 & 0.87 \\
\hline Marrakech & 0.9 & 672 & 0.84 \\
\hline Meknes & 0.95 & -14 & 0.85 \\
\hline Midelt & 0.85 & 740 & 0.81 \\
\hline Nador & 0.95 & -214 & 0.85 \\
\hline Nousar & 0.95 & 92 & 0.86 \\
\hline Ouarzazate & 0.85 & 1151 & 0.83 \\
\hline Oujda & 0.96 & -81 & 0.79 \\
\hline Errachidia & 0.76 & 1372 & 0.78 \\
\hline Safi & 0.96 & 214 & 0.78 \\
\hline Sidi Ifni & 0.63 & 1341 & 0.78 \\
\hline Sidi Sliman & 0.96 & -75 & 0.85 \\
\hline Tangier & 0.97 & -114 & 0.81 \\
\hline Tantan & 0.65 & 1534 & 0.77 \\
\hline Taza & 0.94 & -29 & 0.85 \\
\hline Tetouan & 1 & 429 & 0.83 \\
\hline Rabat & 1.03 & -317 & 0.93 \\
\hline
\end{tabular}

missing values over 250390 measured values or $0.006 \%$ ) throughout the 10-year measurement period (2009-2018).

\section{Presentation of the Method}

This work aims at establishing a solar data bank of energetic components $\left(H_{j}, H_{b j}, H_{d j}\right.$, and $\left.H_{\beta j}\right)$ and spectral components $\left(H_{\mathrm{UVT}}, H_{\mathrm{PAR}}\right.$, and $\left.H_{\mathrm{IR}}\right)$ all over Morocco. However, this work will be completed in two main steps: firstly, we used one year's worth of measurements of the different components of the solar radiation, provided by the National Meteorological Department, to establish the extrapolation equations between Fez's global radiation and the global radiation of twenty-eight other sites. As well as with the same measurements, for each sites, we developed the correlation equations between the global solar radiation and the other solar radiation components. Secondly, from ten years of Fez station's daily global radiation measurements and through the extrapolation equations, we were able to estimate the global radiation of all Moroccan cities. Then, by using the obtained global radiation data and the correlation equations,
TABLE 5: Correlation equations for the daily values of the spectral components of solar radiation $\left(\mathrm{Wh} / \mathrm{m}^{2}\right)$ in function of global solar radiation $H\left(\mathrm{Wh} / \mathrm{m}^{2}\right)$ for the three sky conditions.

\begin{tabular}{lcc}
\hline Clarity index intervals & Correlation equations & $R^{2}$ \\
\hline \multirow{3}{*}{$K_{t} \leq 0.35$} & $H_{\mathrm{uv}}=0.048 \mathrm{H}$ & 0.97 \\
& $H_{\mathrm{PAR}}=0.488 \mathrm{H}$ & 0.99 \\
& $H_{\mathrm{IR}}=0.46 \mathrm{H}$ & 0.99 \\
\hline \multirow{3}{*}{$0.35<K_{t} \leq 0.65$} & $H_{\mathrm{uv}}=0.044 \mathrm{H}$ & 0.97 \\
& $H_{\mathrm{PAR}}=0.484 \mathrm{H}$ & 0.99 \\
& $H_{\mathrm{IR}}=0.471 \mathrm{H}$ & 0.99 \\
$K_{t}>0.65$ & $H_{\mathrm{uv}}=0.04 \mathrm{H}$ & 0.98 \\
& $H_{\mathrm{PAR}}=0.478 \mathrm{H}$ & 0.99 \\
& $H_{\mathrm{IR}}=0.478 \mathrm{H}$ & 0.99 \\
\hline
\end{tabular}

TABLE 6: The performance of models used to estimate daily solar irradiation for the Rabat site.

\begin{tabular}{lccccc}
\hline & RMBE & $\begin{array}{c}\text { Mean } \\
\text { difference }\end{array}$ & MAPE & RMSE & $\begin{array}{c}\text { Number } \\
\text { of values }\end{array}$ \\
\hline Global radiation & 5.42 & 252 & 12.14 & 14.88 & 290 \\
Diffuse radiation & -3.63 & -77 & 12.71 & 15.82 & 257 \\
Direct radiation & 1.45 & 21.6 & 14.68 & 17.52 & 234 \\
Inclined radiation & -6.21 & -365 & 6.35 & 7.46 & 323 \\
\hline
\end{tabular}

we predicted the other components of solar radiation $\left(H_{j}, H_{b j}, H_{d j}, H_{\beta j}, H_{\mathrm{UVT}}, H_{\mathrm{PAR}}\right.$, and $\left.H_{\mathrm{IR}}\right)$.

Thus, we have been able to build a database of different components of solar radiation over ten years for the 29 Moroccan sites. In the end, all the obtained results were tested and validated by using a new series of measurements carried out on the five mentioned stations.

\section{Extrapolation and Correlation Equations for Daily Solar Components}

5.1. Extrapolation of the Daily Global Solar Irradiation. The estimation of global solar radiation can be effected by using several methods, such as the empirical model, ANN model, and satellite imagery. However, the use of these models requires knowledge of several variables and the availability of a database that spans several years. On the other hand, databases are not often available, especially for isolated sites. As a result, to remedy this problem, we developed, as part of this work, an extrapolation method to estimate the global solar radiation. Primarily, this method consists of estimating the global radiation at site where we do not have measurements, from the global radiation measured at another site.

In the first step of this method, from one year of measurements of global radiation for all Moroccan sites, we looked for to establish correlation equations between the global radiation of the different sites and the global radiation of 


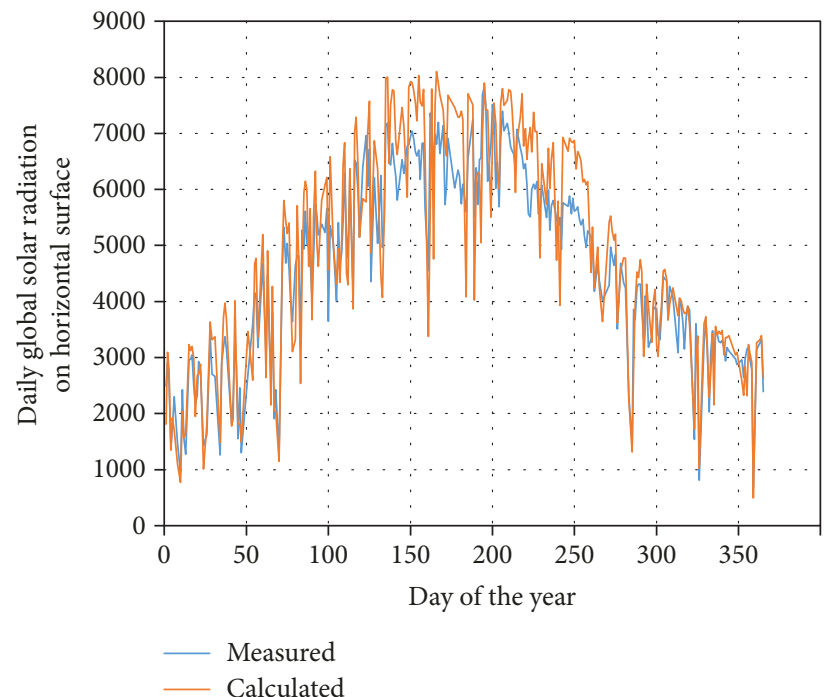

(a)

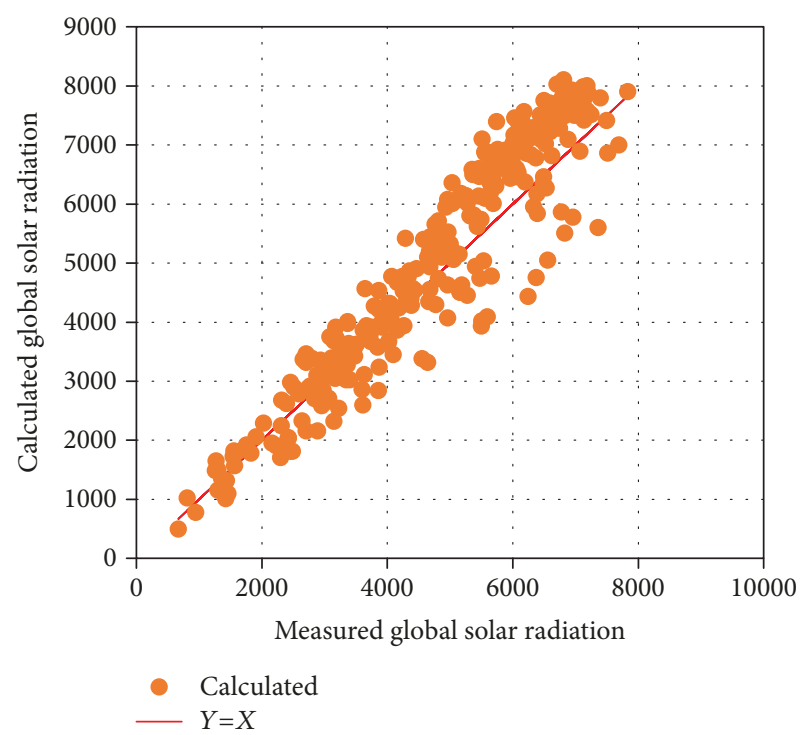

(b)

FIGURE 1: Comparison between measured and estimated values of global radiation.

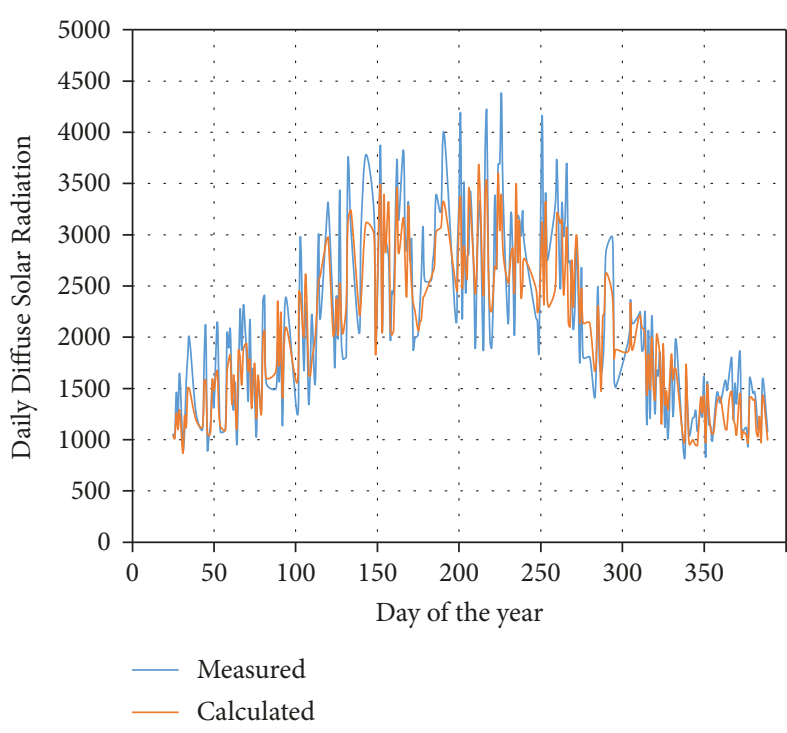

(a)

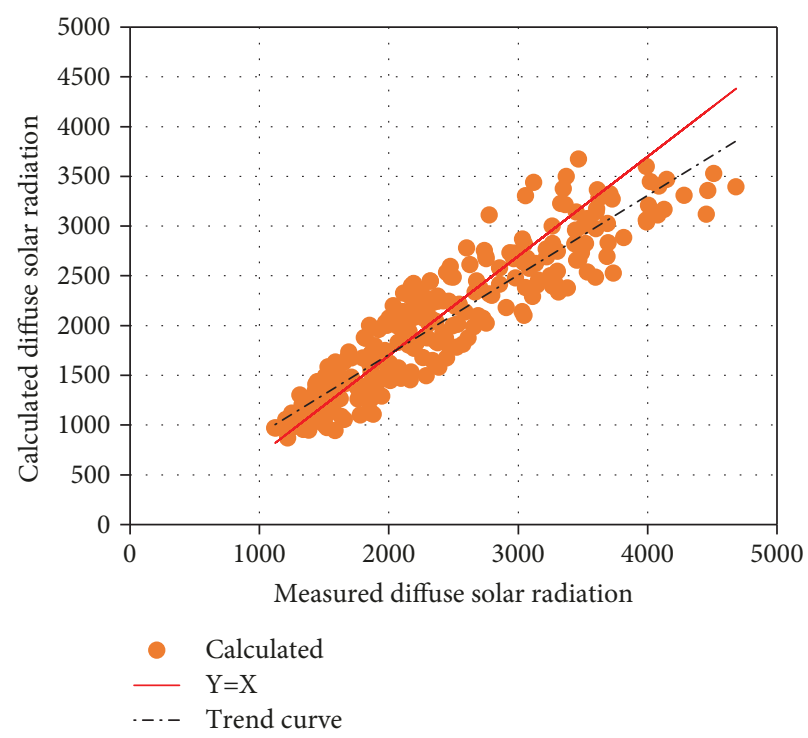

(b)

Figure 2: Comparison between measured and estimated values of diffuse radiation using the Collares-Pereira and Rabl's model.

the reference site. For this, we plotted the global radiation values for each site $\left(H_{j}\right)$ according to the global radiation values of Fez's site $\left(H_{f}\right)$, chosen as a reference site.

The obtained shape of the cloud point led us to linear correlations of the type:

$$
H_{j}=a_{\text {site }} H_{f}+b_{\text {site }} .
$$

The coefficients of correlations $a_{\text {site }}$ and $b_{\text {site }}$ depend strongly on the geographical coordinates of the site and the status of the atmosphere [43]. Table 4 gathers the obtained values from these coefficients for all Moroccan sites.

5.2. Daily Diffuse Solar Irradiation Estimation. The diffuse component is an important factor for evaluating the performance of solar thermal or solar photovoltaic systems. However, several models, involving the clearness index $K_{t}=\left(H_{j l} H_{0}\right)$ [44], have been made to estimate this component. Among these models, we can cite the Ruth and Chant's model, the Collares-Pereira and Rabl's model, and the Liu and Jordan model [45]. 




(a)

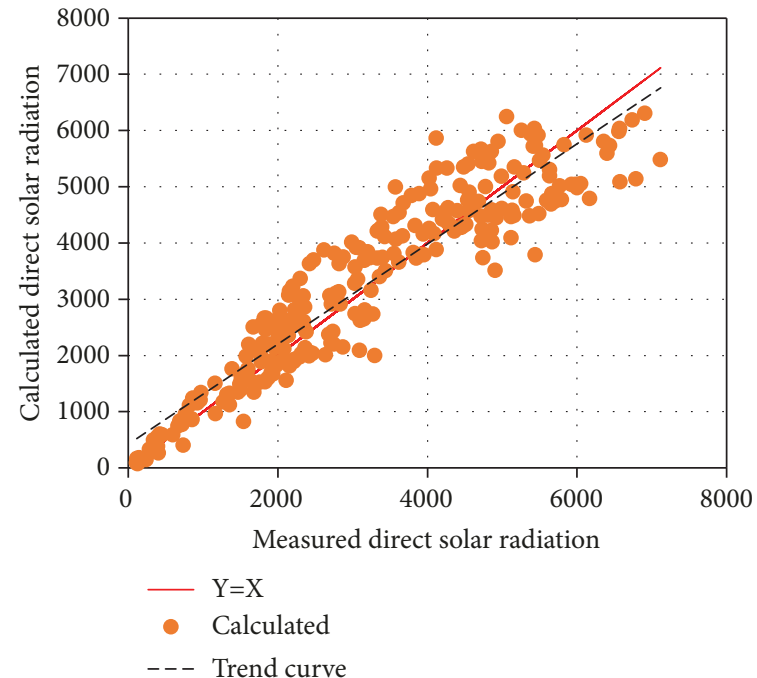

(b)

Figure 3: Comparison between measured and estimated direct radiation values.

To find the valid model for Morocco, we compared the estimated diffuse by the mentioned models with the measured diffuse. Then we concluded that the Collares-Pereira and Rabl's model is the most adequate because it produces a minimal error that does not exceed 5\%. This model is illustrated by the following equations [42]:

$K_{d}=\left\{\begin{array}{l}0.99 ; K_{t}<0.17, \\ 14.648 K_{t}^{4}-21.856 K_{t}^{3}+9.473 K_{t}^{2}-2.272 K_{t}+1.188 ; 0.17 \leq K_{t} \leq 0.8 .\end{array}\right.$

Knowing the diffuse solar irradiation, the direct solar irradiation can easily be inferred by the following equation [46]:

$$
H_{b j}=H_{j}-H_{d j}
$$

5.3. Estimation of Daily Global Solar Irradiations on an Inclined Plane. The solar flux received by an inclined surface consists of three components: a direct component from the solar disk, a diffuse component from the entire celestial vault, and a component reflected by the surrounding soil.

The estimation of the direct component is completed by simple geometric transposition of the direct irradiation of a horizontal plane $H_{b j}$. On the other hand, for the diffuse component, several models have been proposed for its estimation $[45,47,48]$. Consequently, an earlier study showed that the isotropic model of Liu and Jordan is the most valid for our sites [49]. Most of the cases, the reflected component is the lowest of the three components, and it is generally assumed isotropic.
TABLE 7: Errors obtained according to clarity index using Rabat measurements.

\begin{tabular}{lccc}
\hline & $\begin{array}{c}H_{\mathrm{UVT}} \text { relative } \\
\text { error }(\%)\end{array}$ & $\begin{array}{c}H_{\mathrm{PAR}} \text { relative } \\
\text { error }(\%)\end{array}$ & $\begin{array}{c}H_{\mathrm{IR}} \text { relative } \\
\text { error }(\%)\end{array}$ \\
\hline$K_{t}<0.35$ & 3.8 & 2.4 & 2.2 \\
$0.35<K_{t} \leq 0.65$ & 1.0 & 1.8 & 2.1 \\
$K_{t}>0.65$ & 1.0 & 1.1 & 1.1 \\
\hline
\end{tabular}

The general expression of the inclined daily global solar irradiation with an angle $\beta$ is given by [49]:

$$
\begin{aligned}
& H_{\beta j}=R_{b} H_{b j}+H_{d j} \frac{1+\cos (\beta)}{2}+\rho H \frac{1-\cos (\beta)}{2} \text {. } \\
& \text { direct diffuse reflected }
\end{aligned}
$$

$R_{b}$ is the transposition factor of the direct radiation from a horizontal plane to an inclined plane. It was calculated for a south-oriented plane, by the equation as follows:

$$
\begin{aligned}
R_{b} & =\frac{\cos \left(\delta_{j}\right) \cdot \cos (\varphi-\beta) \cdot \sin \left(\omega_{j \beta}\right)+\omega_{j \beta} \cdot \sin \left(\delta_{j}\right) \cdot \sin (\varphi-\beta)}{\cos \left(\delta_{j}\right) \cdot \cos \left(\varphi \varphi \cdot \sin \left(\omega_{j}\right)+\omega_{j} \cdot \sin \left(\delta_{j}\right) \cdot \sin (\varphi)\right.}, \\
\omega_{j \beta} & =\min \left\{\operatorname { a r c o s } \left(-\tan \left(\delta_{j}\right) \cdot \tan (\phi), \operatorname{arcos}\left(-\tan \left(\delta_{j}\right) \cdot \tan (\phi-\beta)\right\},\right.\right.
\end{aligned}
$$

where $\omega_{j \beta}$ is the time angle of the sunset on the inclined plane.

The values taken by the tilt angle $\beta$, correspond to the characteristic inclinations relative to the latitude of each site: $\beta=\varphi, \beta=\varphi+20, \beta=\varphi-20$, and $\beta=90$ corresponding to the vertical facades.

5.4. Estimation of the Spectral Components of Solar Radiation. Some applications of solar energy require knowledge of the 


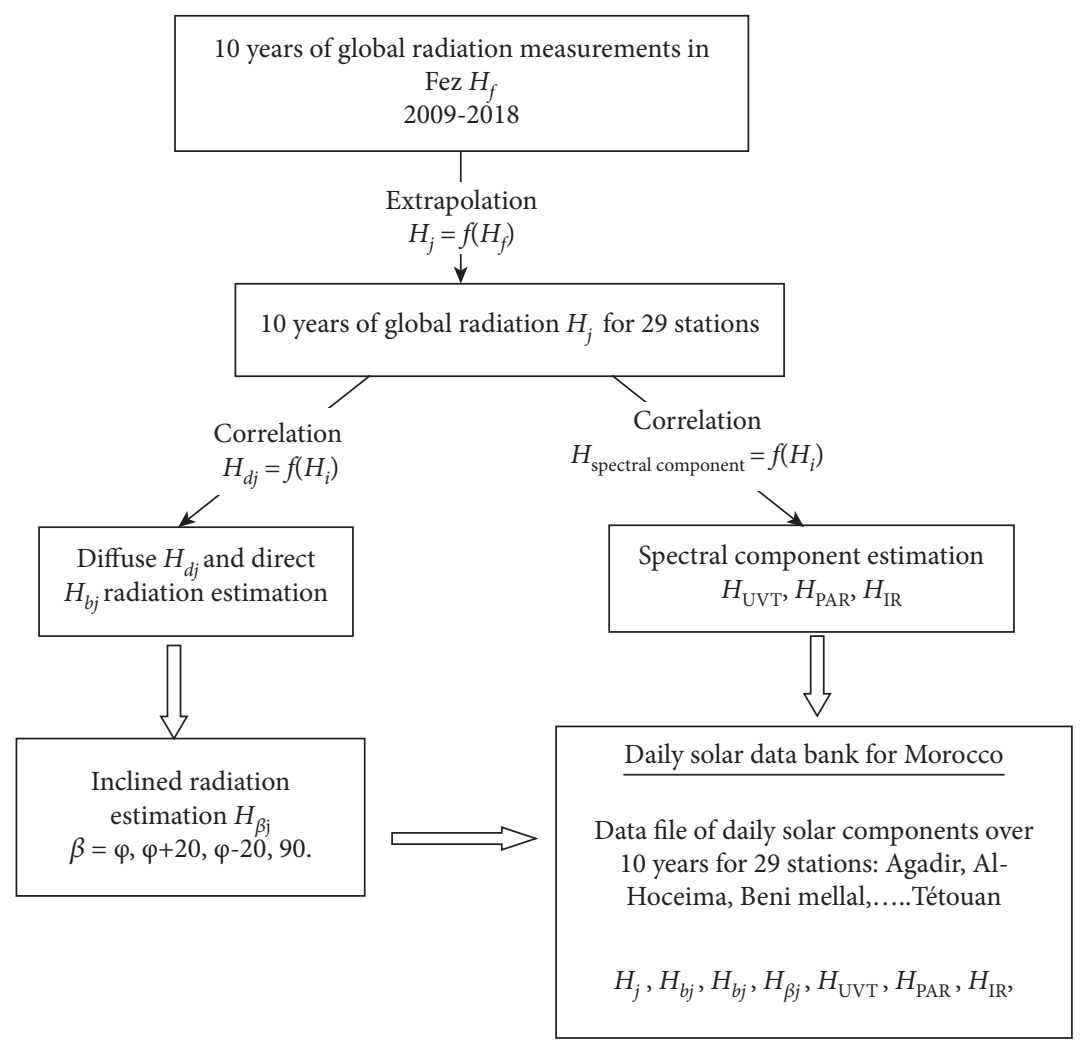

FIGURE 4: Flowchart of the building steps of the daily solar data bank for Morocco.

TABLE 8: Sample data file resulting from different estimations.

\begin{tabular}{|c|c|c|c|c|c|c|c|c|c|c|c|}
\hline Year & $\mathrm{Nj}$ (day) & Global & Diffuse & Direct & Inclined $(\varphi+20)$ & Inclined $(\varphi-20)$ & Inclined $(\varphi)$ & Inclined (90) & $H_{\mathrm{UVT}}$ & $H_{\mathrm{PAR}}$ & $H_{\text {IR }}$ \\
\hline 2011 & 1 & 2808.4 & 1164.7 & 1643.7 & 4683.6 & 3552.5 & 4375 & 4171.9 & 123.6 & 1359.3 & 1322.8 \\
\hline 2011 & 2 & 2766.6 & 1202.5 & 1564.1 & 4526.3 & 3470.8 & 4246.2 & 4015.1 & 121.7 & 1339 & 1303.1 \\
\hline 2011 & 3 & 2435.5 & 1396.1 & 1039.4 & 3499.8 & 2894.4 & 3383.5 & 3018.3 & 107.2 & 1178.8 & 1147.1 \\
\hline 2011 & 4 & 2515.6 & 1368.7 & 1146.9 & 3710.5 & 3021.7 & 3565.1 & 3217.8 & 110.7 & 1217.6 & 1184.8 \\
\hline 2011 & 5 & 2629.9 & 1318.1 & 1311.8 & 4028 & 3208.8 & 3836.5 & 3520.3 & 115.7 & 1272.9 & 1238.7 \\
\hline 2011 & 6 & 2844.2 & 1192.5 & 1651.7 & 4669 & 3574.9 & 4378.7 & 4136.5 & 125.1 & 1376.6 & 1339.6 \\
\hline 2011 & 7 & 2396 & 1444.7 & 951.3 & 3314.2 & 2805.5 & 3235.5 & 2827.6 & 105.4 & 1159.7 & 1128.5 \\
\hline 2011 & 8 & 2797.1 & 1250 & 1547.1 & 4458.7 & 3472.3 & 4209.8 & 3922.6 & 123.1 & 1353.8 & 1317.4 \\
\hline 2011 & 9 & 2608.6 & 1375 & 1233.6 & 3860 & 3139.2 & 3708 & 3341.1 & 114.8 & 1262.6 & 1228.7 \\
\hline 2011 & 10 & 3083.6 & 1077.5 & 2006.1 & 5291.3 & 3954.6 & 4918.1 & 4715.2 & 135.7 & 1492.5 & 1452.4 \\
\hline 2011 & 11 & 3201.2 & 1010.7 & 2190.5 & 5617.9 & 4147.9 & 5198.1 & 5022.8 & 128 & 1530.2 & 1530.2 \\
\hline 2011 & 12 & 2695.6 & 1368.1 & 1327.5 & 4022.1 & 3256.3 & 3857.7 & 3480.8 & 118.6 & 1304.7 & 1269.6 \\
\hline 2011 & 13 & 3228.4 & 1024.4 & 2204 & 5613.5 & 4167.3 & 5206 & 5002.4 & 129.1 & 1543.2 & 1543.2 \\
\hline 2011 & 14 & 3130.4 & 1110.8 & 2019.6 & 5265.8 & 3982.2 & 4918.6 & 4660.2 & 137.7 & 1515.1 & 1474.4 \\
\hline 2011 & 15 & 3253.6 & 1042.2 & 2211.4 & 5595.9 & 4181 & 5203.6 & 4967.9 & 130.1 & 1555.2 & 1555.2 \\
\hline 2011 & 16 & 3160.8 & 1126.4 & 2034.4 & 5264.7 & 4005 & 4930 & 4642.1 & 139.1 & 1529.8 & 1488.7 \\
\hline 2011 & 17 & 2880.3 & 1341.1 & 1539.2 & 4373.3 & 3507.7 & 4181.2 & 3783.1 & 126.7 & 1394.1 & 1356.6 \\
\hline 2011 & 18 & 3239.3 & 1114.8 & 2124.5 & 5395.9 & 4106.4 & 5055 & 4748.2 & 142.5 & 1567.8 & 1525.7 \\
\hline 2011 & 19 & 2272.2 & 1593.9 & 678.3 & 2748 & 2531.8 & 2782.5 & 2248.4 & 100 & 1099.7 & 1070.2 \\
\hline 2011 & 20 & 3094.1 & 1268.5 & 1825.6 & 4850.4 & 3821.8 & 4606.8 & 4210.1 & 136.1 & 1497.5 & 1457.3 \\
\hline 2011 & 21 & 3321.7 & 1132 & 2189.7 & 5464.3 & 4190.8 & 5136.6 & 4781.2 & 146.2 & 1607.7 & 1564.5 \\
\hline
\end{tabular}




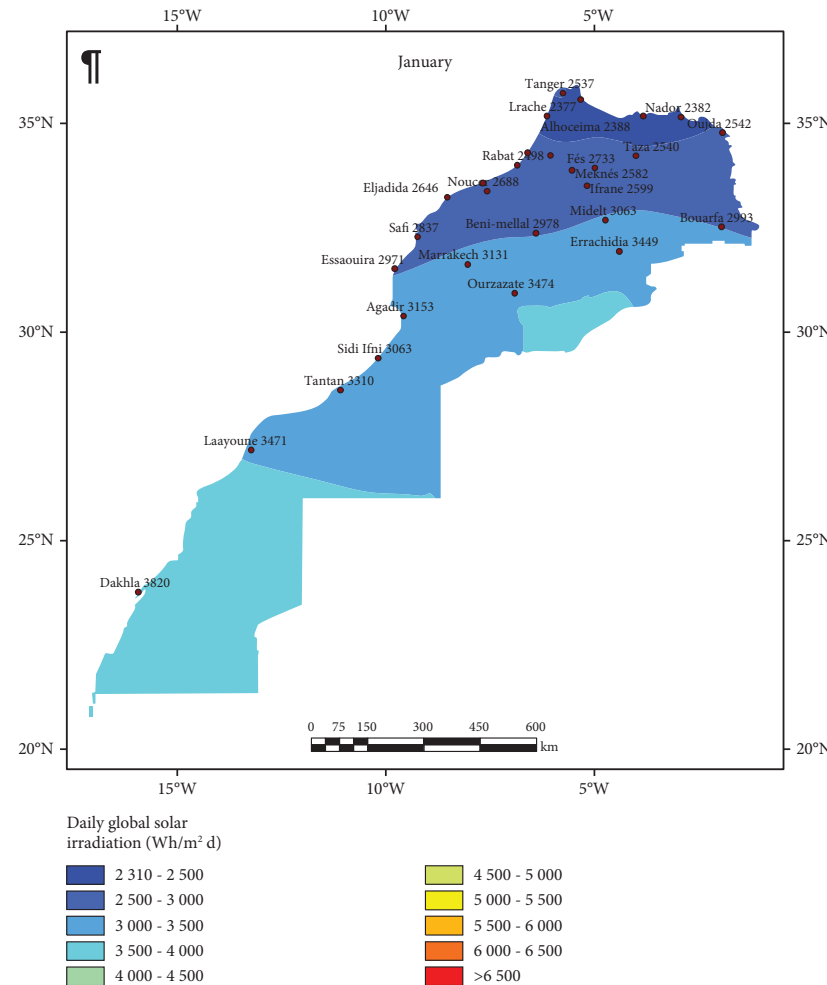

(a)

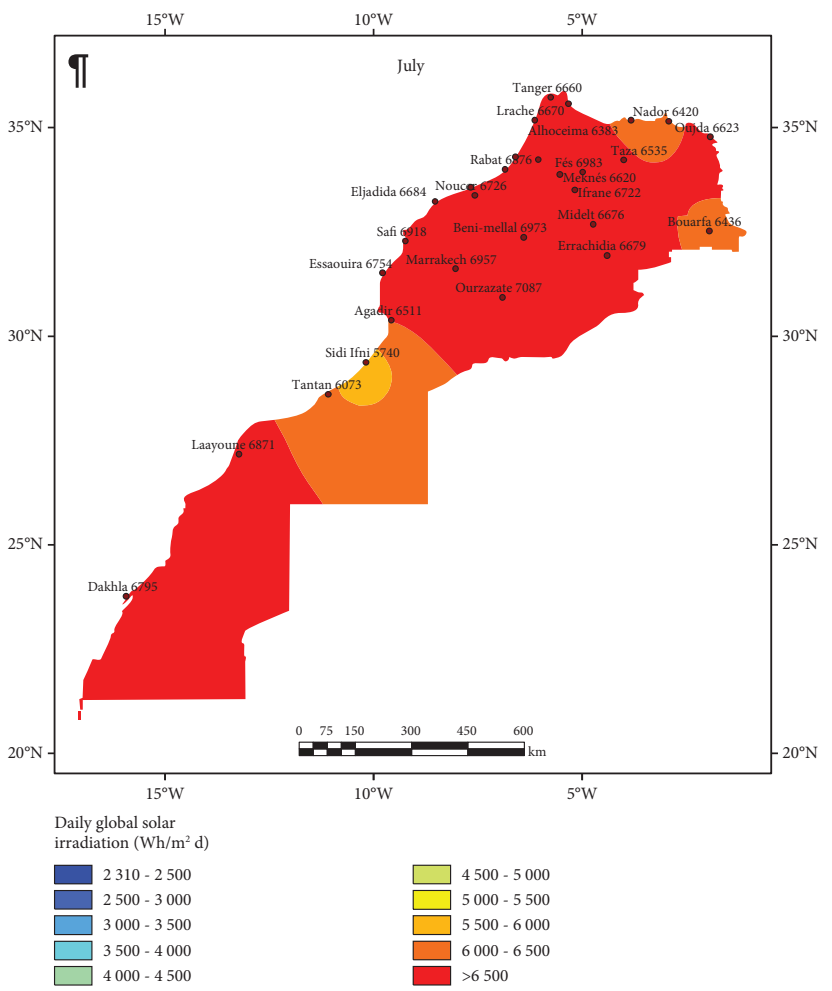

(c)

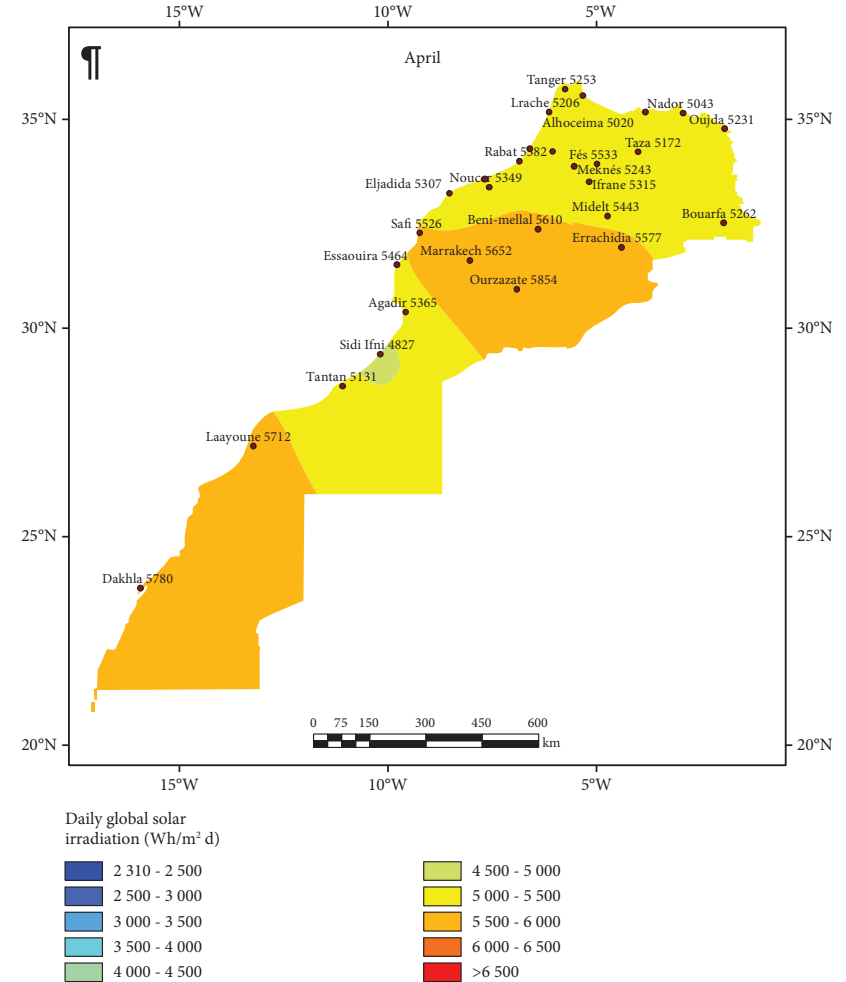

(b)

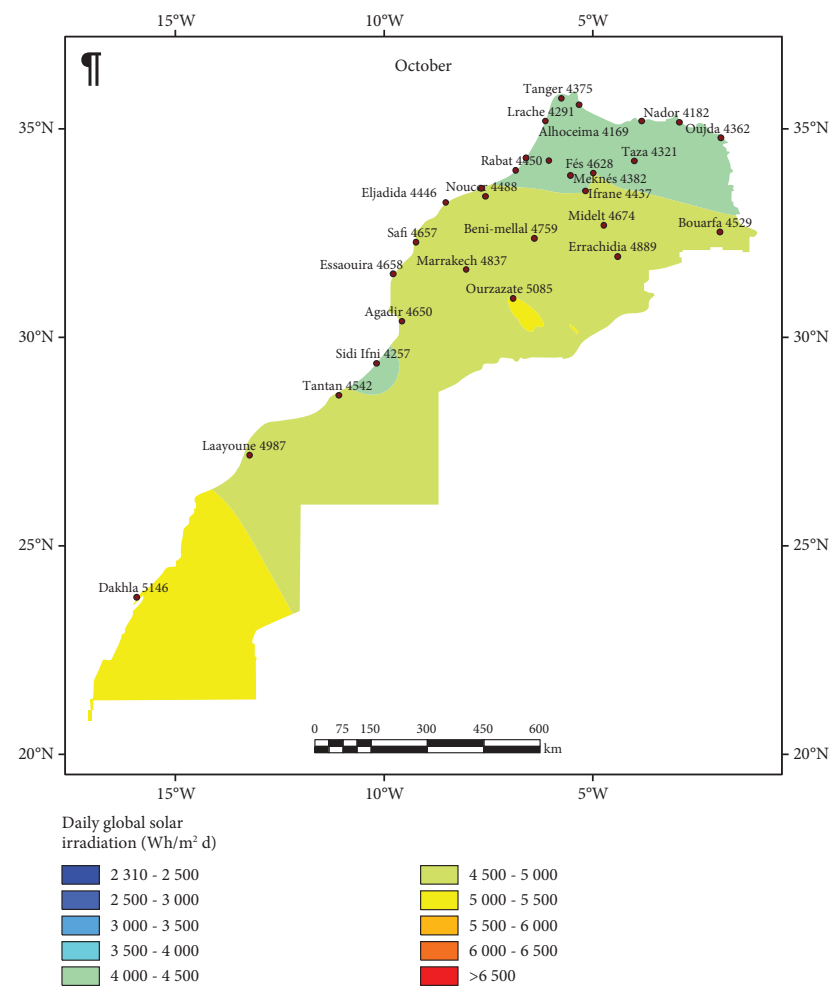

(d)

FIGURE 5: Maps of the monthly average values of daily global irradiations on a horizontal plane, coming from Morocco. Maps of global solar radiation on a horizontal plane $(\mathrm{a}-\mathrm{d})$.

spectral components of solar radiation, namely, the ultraviolet component $\left(H_{\mathrm{UVT}}\right)$ which is involved in the study of the atmosphere and the variations in the ozone layer thickness.
The photosynthetically active component noted as $H_{\mathrm{PAR}}$ (photosynthetically active radiation) intervenes during the photosynthesis process and plant development; knowing the 


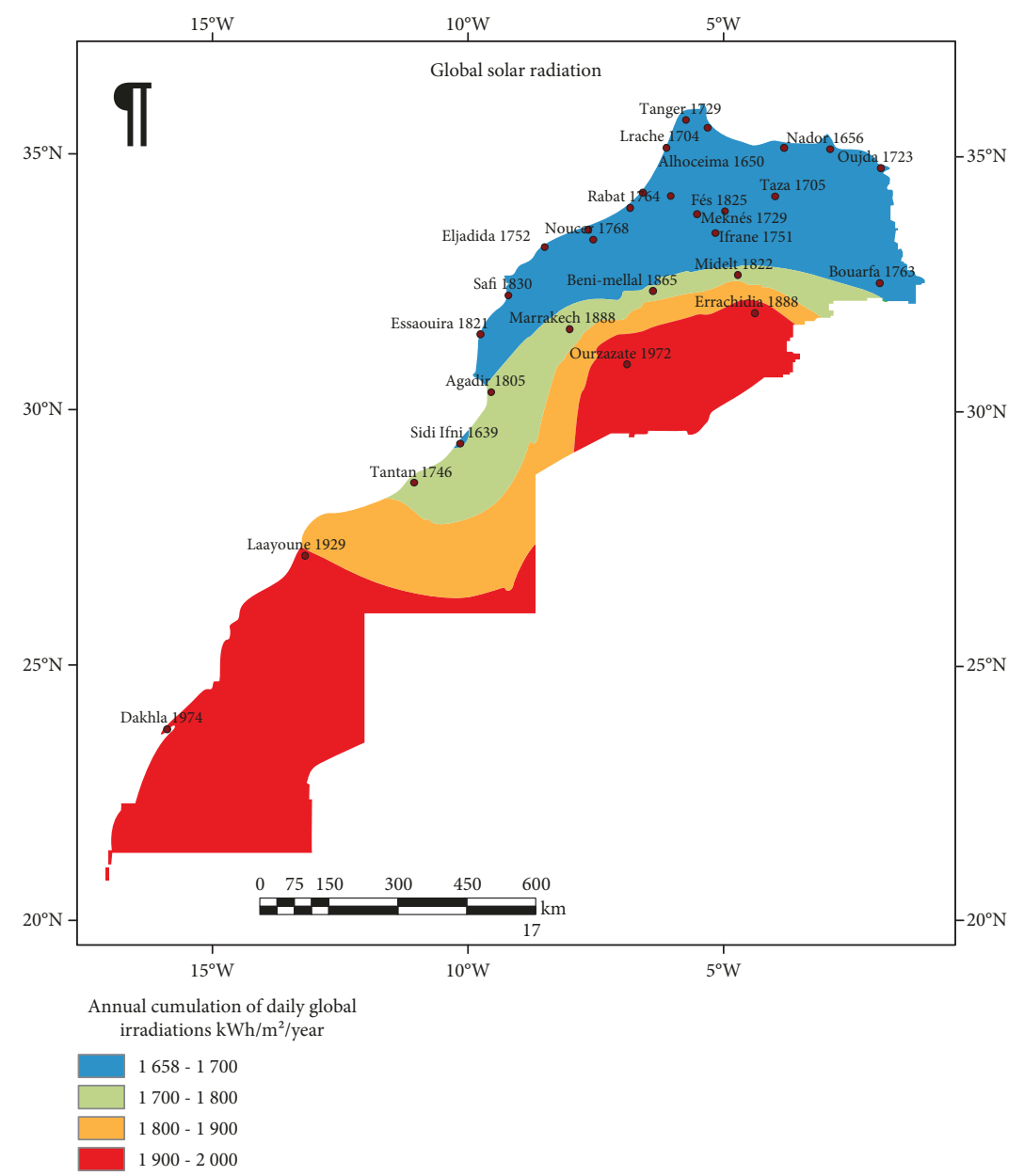

FIGURE 6: Map of annual cumulation of daily global irradiations on a horizontal plane incident in the Moroccan territory. Map of global solar radiation on a horizontal plane.

$H_{\text {PAR }}$ value at various sites allows for the appropriate choice of adapted crops. Lastly, the infrared component $H_{\mathrm{IR}}$ is used by satellite techniques to determine the total atmospheric column of the water vapor used by meteorology for the climate prediction [50].

Based on one year's worth of measurements of the different components of the solar radiation provided by the National Meteorological Department, we noticed that the variations of the global radiation and the spectral components, functioning in time, have the same rate. As a result, we searched correlation equations connecting the global solar radiation to the spectral solar radiation.

For this, we graphed each spectral component according to the global radiation, which gave us linear equations of the form $y=a x$. To improve the correlation coefficients, we defined three intervals according to the meteorological state of the day characterized by its clearness index $K_{t}$ [51]. The results are presented in Table 5.

\section{Performance Evaluation and Model Validation}

To evaluate the quality of the models used to estimate the solar radiation components, we compared the estimated values generated by the different models against the measured values by using the usual statistical indicators such as the relative error (RMBE), the mean absolute error (MAE), the mean absolute percentage error (MAPE), and the mean squared error (RMSE) [34, 38].

$$
\begin{aligned}
\mathrm{RMBE} & =100 \frac{\sum_{i=0}^{n}\left(p_{i}-m_{i}\right)}{\sum_{i=0}^{n} m_{i}}, \\
\mathrm{MAE} & =\frac{\sum_{i=0}^{n}\left|p_{i}-m_{i}\right|}{N}, \\
\mathrm{MAPE} & =\frac{1}{N} \sum_{i=0}^{n}\left|\frac{p_{i}-m_{i}}{m_{i}} * 100\right|, \\
\mathrm{RMSE} & =\frac{100}{\bar{m}} \sqrt{\frac{\sum_{i=0}^{n}\left(p_{i}-m_{i}\right)^{2}}{N} .}
\end{aligned}
$$

6.1. Validation of Energy Component Models. Using the measurements provided by the Solar Energy and Environment Laboratory's station network, we were able to calculate the statistical indicator and validate the estimation models. However, these calculations were effected 


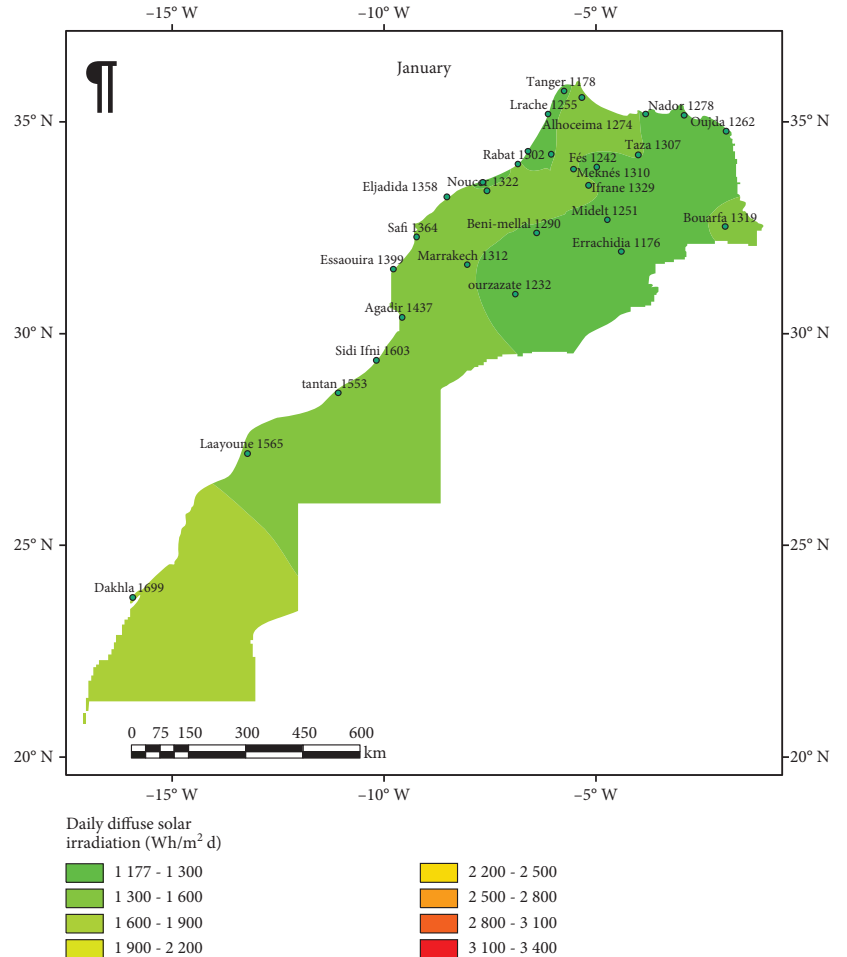

(a)

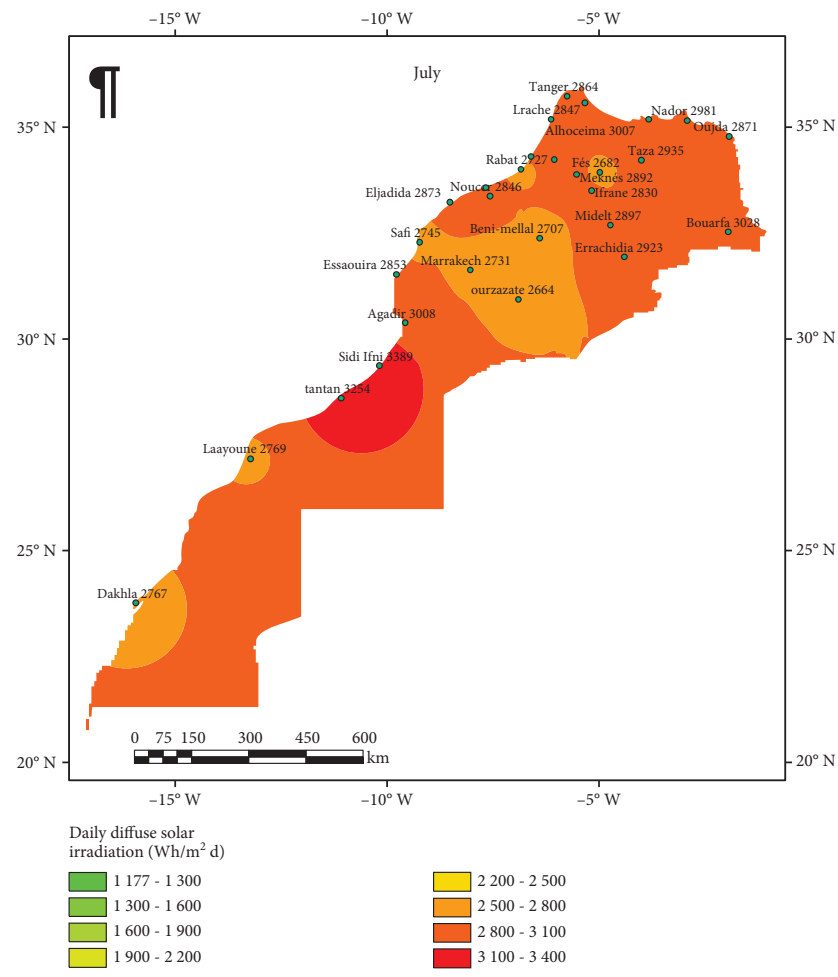

(c)

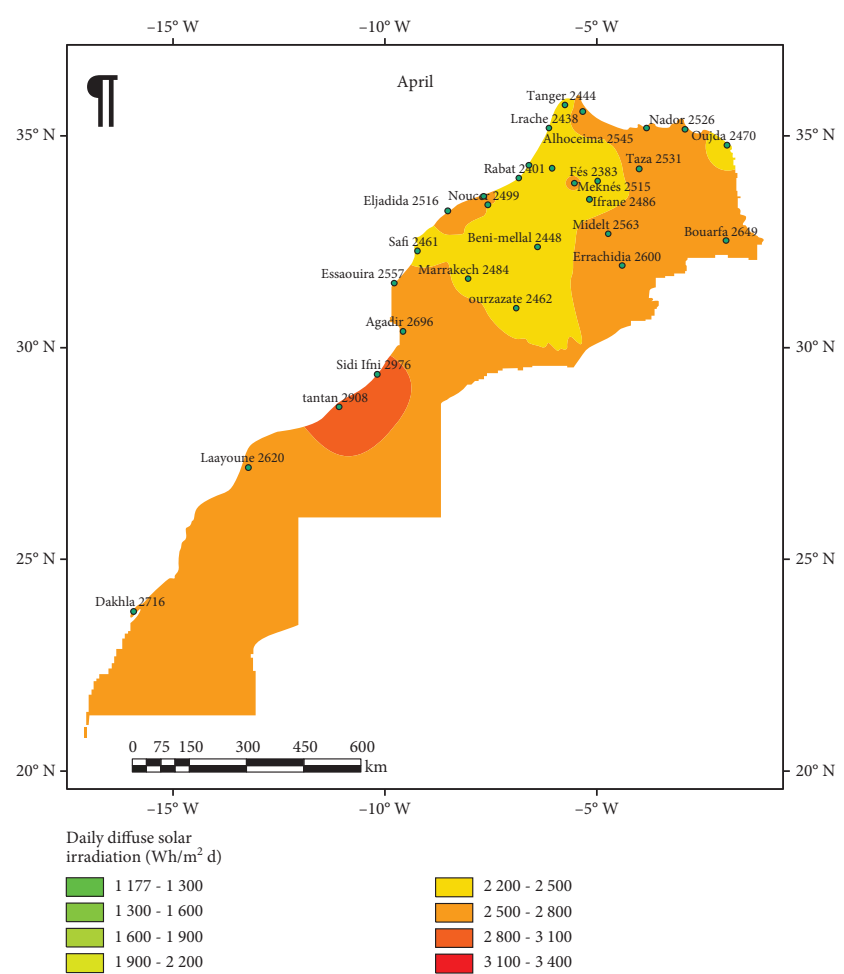

(b)

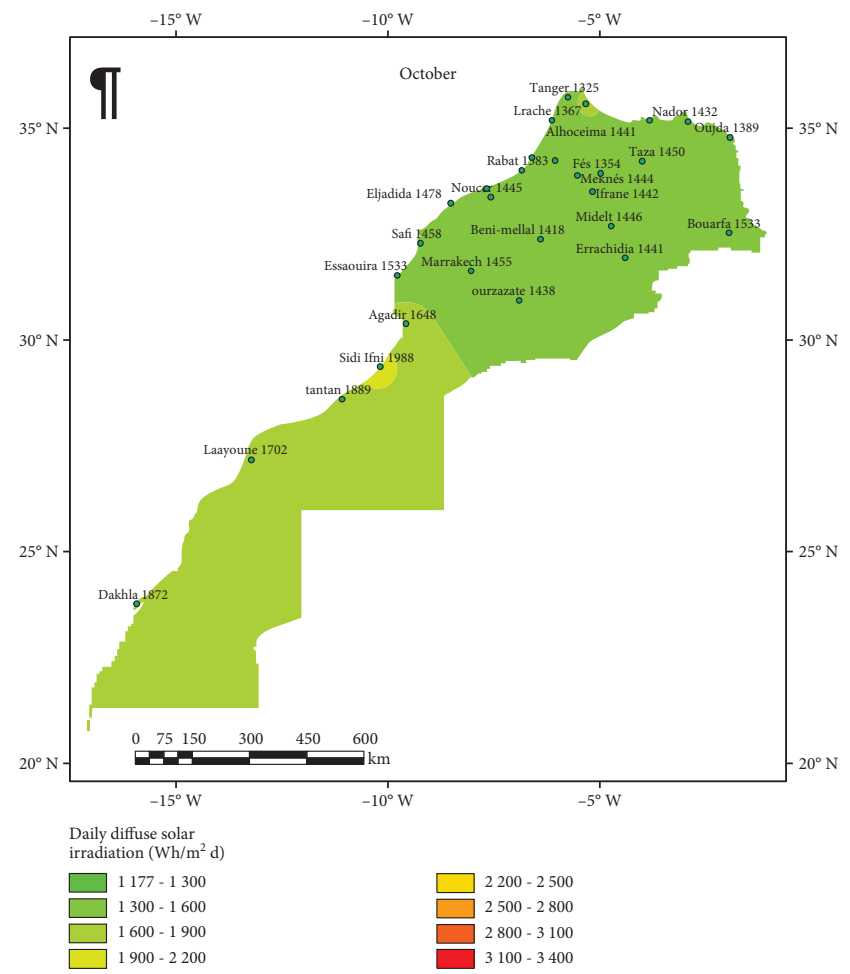

(d)

Figure 7: Maps of the monthly average values of daily diffuse irradiations on a horizontal incident plane in Morocco. Maps of diffuse solar radiation on a horizontal plane $(\mathrm{a}-\mathrm{d})$.

for all sites previously mentioned. Table 6 and Figures 1-3 are examples of the obtained results for the Rabat Site.
6.2. Validating Spectral Components. The formulas for estimating the spectral components of solar radiation from the measurement of global solar radiation were developed 


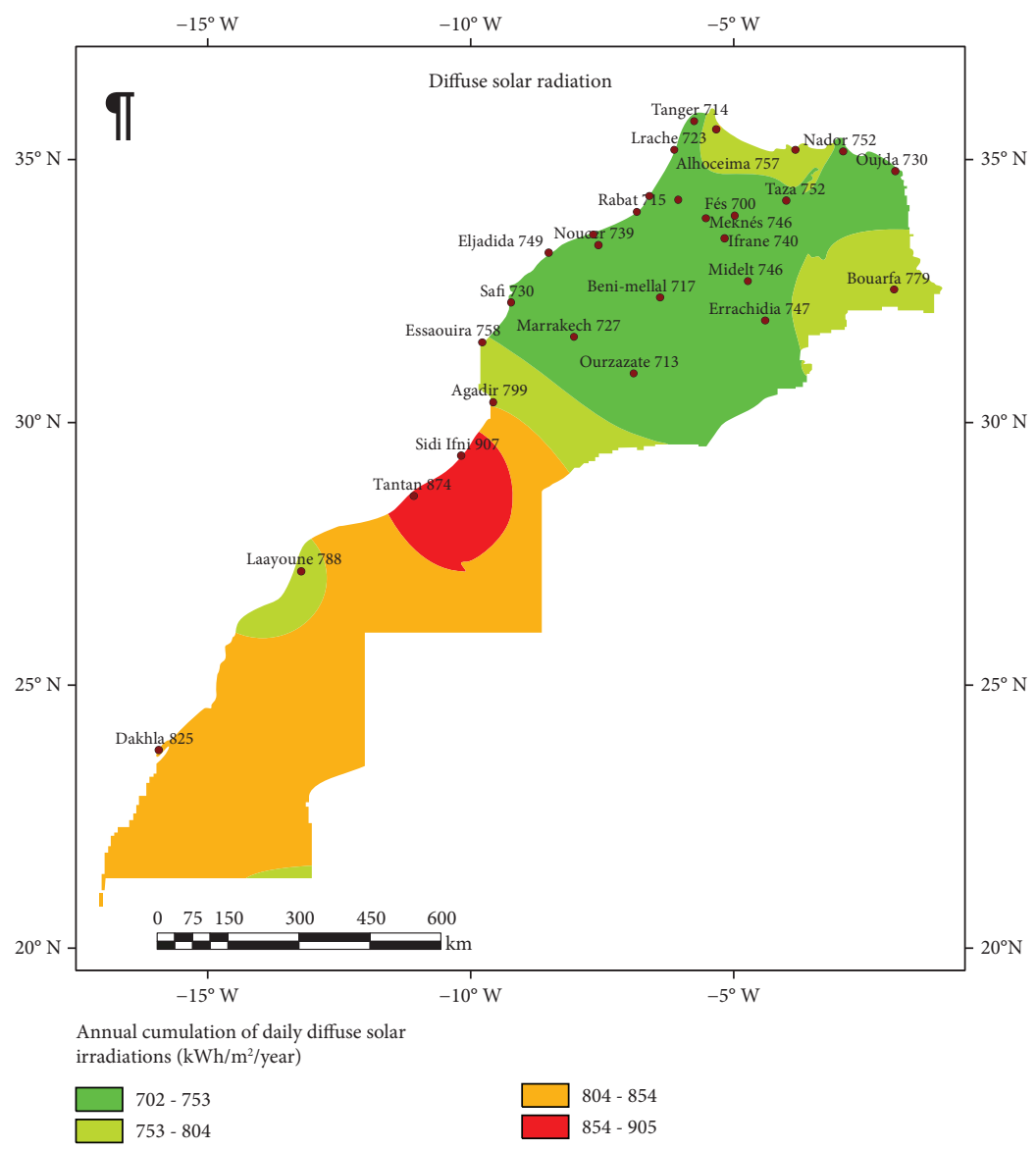

FiguRE 8: Map of annual cumulation of daily diffuse irradiations on a horizontal plane incident in the Moroccan territory. Map of diffuse solar radiation on a horizontal plane.

according to the state of the day characterized by its $K_{t}$ clarity index. The results in Table 7 revealed that the proposed models estimate the spectral components with remarkable accuracy since the maximum deviations obtained do not exceed $4 \%$.

For all obtained equations, we found that the conditions of the sky (overcast, moderately covered, and clear) have a significant influence mainly on the $H_{\mathrm{UV}} / H_{j}$ fraction. This result is similarly found to the one in Brazil [52]. An estimate of the ultraviolet component that ignores the state of the sky can induce an error of up to $10 \%$. However, the $H_{\mathrm{PAR}} / H_{j}$ and $H_{\mathrm{IR}} / H_{j}$ fractions are less influenced by cloud cover.

\section{Application: Building a Ten-Year Database}

After having established and validated the extrapolation and correlation equations, we applied them to estimate the different solar radiation components for the different Moroccan sites. The obtained results constitute a solar data bank for all over Morocco for ten years.

Figure 4 represents the flow-chart summarizing all the steps followed for generating all solar components from the site of the Fez.

\section{Representative Year}

In preproject studies that aimed at sizing solar systems or characterizing the solar radiation potential, it is often necessary to have a minimum of data. Therefore, it is essential to compact the database. Consequently, after having established, for each site, a database for ten years, we were obliged to select a representative year of this database for facilitating the database exploitation.

To determine the representative year, we proceed as follows: for the ten years of estimated values, we calculated an average year. Then, this average year is successively compared to each one of the ten years of estimated values. Consequently, the year with the minimum difference is selected as the representative year.

This work was done for all sites and led us to select 2011 as the representative year for the period between 2009 and 2018.

\section{Results}

After having established and validated the various components of solar radiation, we created a solar data bank for all over Morocco. Thus, for each city, the obtained results 

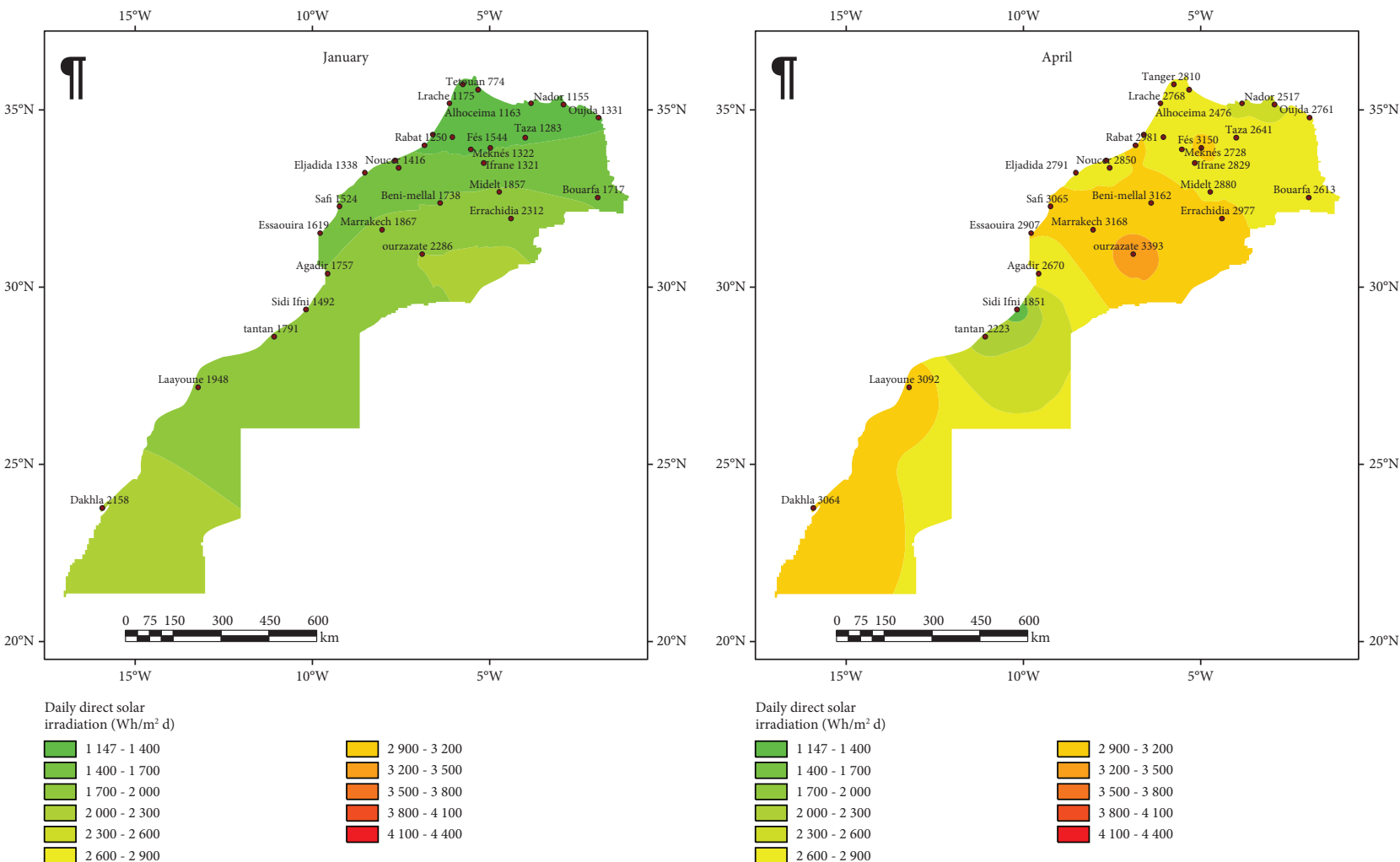

(a)

(b)
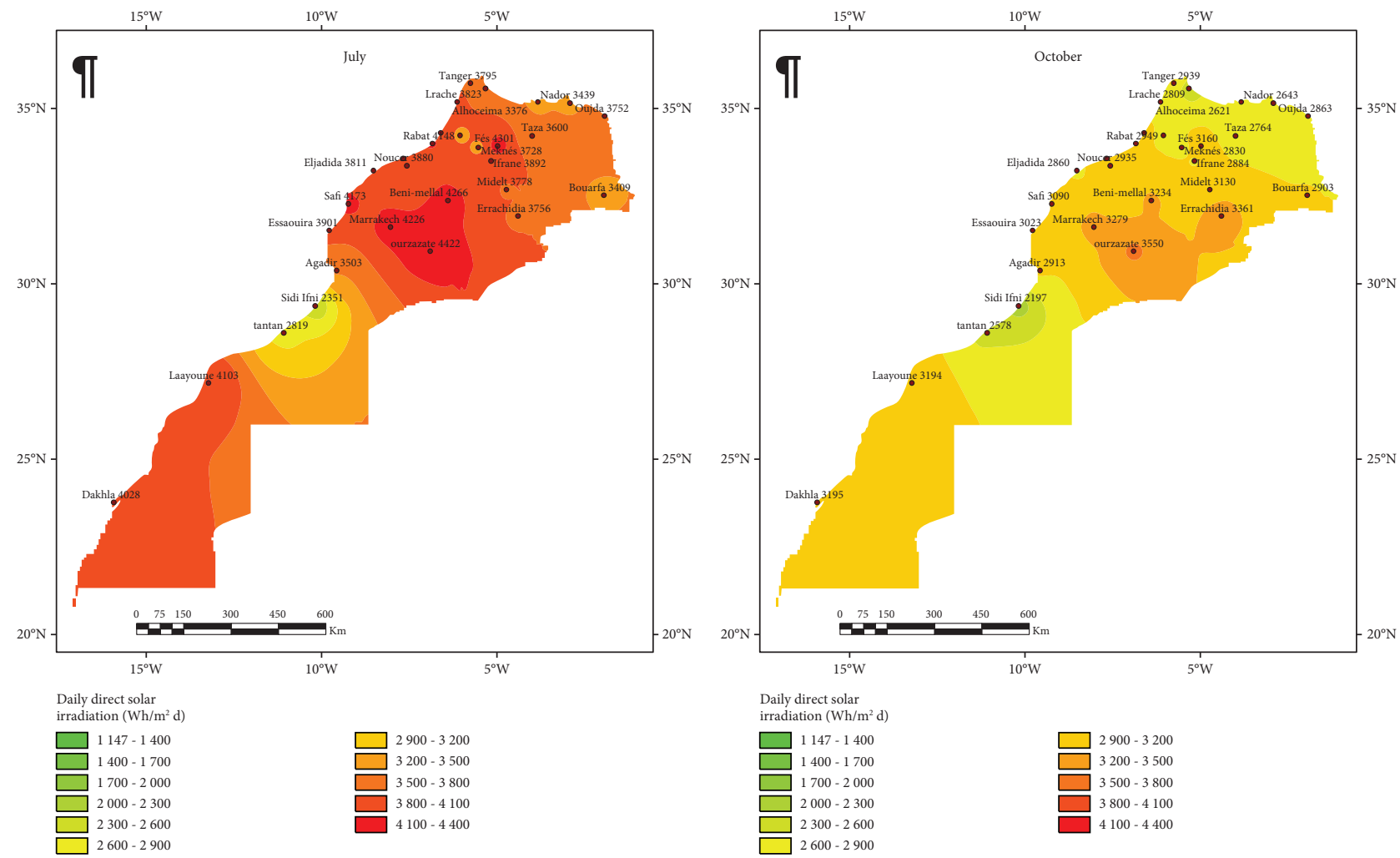

(c)

(d)

FIgURE 9: Maps of the monthly average daily direct irradiation in the Moroccan territory. Maps of direct solar radiation on a horizontal plane $(\mathrm{a}-\mathrm{d})$ 


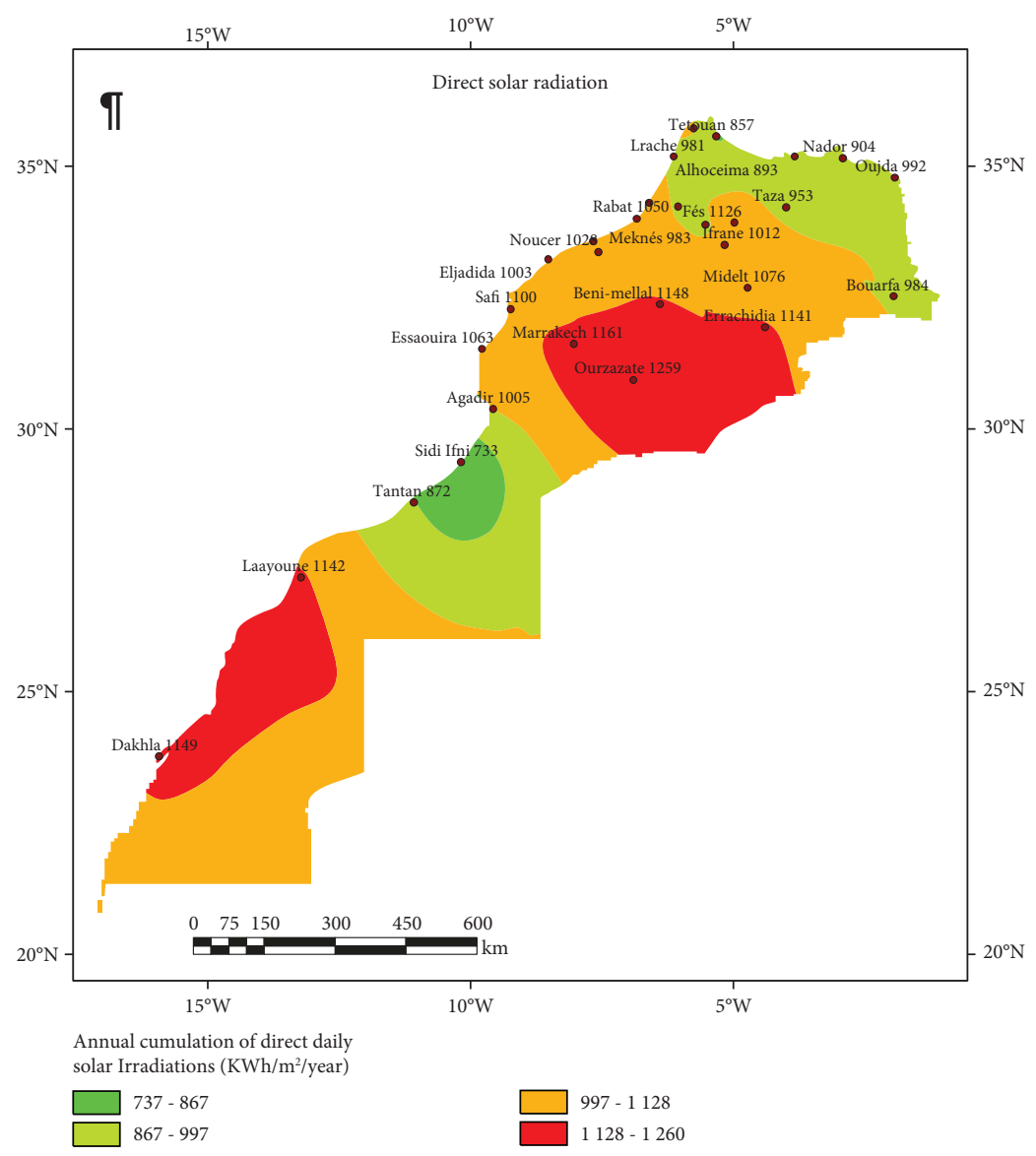

FIgURE 10: Map of annual cumulation of daily direct irradiations on a horizontal plane incident in the Moroccan territory. Map of direct solar radiation on a horizontal plane.

were grouped in two files easily usable; the first one contains the solar components over ten years between 2009 and 2018, and the second contains the solar components of the representative year. However, this second file has the advantage of providing the maximum of climatic information on a site with a minimum of data. This type of file is requested especially for the preliminary project studies.

Table 8 represents a sample data file resulting from different estimations.

In addition, to give an overall view of the results, we projected the obtained values of the solar irradiations on the Moroccan map. Furthermore, In order to reduce the number of figures, we chose to represent only the monthly averages of the daily values of the midseason month of the representative year. Thus, for all cities, we obtained twenty-three maps that gather the various solar irradiations. As a result, for each of the four solar components (global, direct, diffuse, and inclined), we have five maps; four of them represent seasonal values and the last one represent the annual cumulative values. The obtained maps are shown in Figures 5-12. The three spectral components $\left(H_{\mathrm{UVT}}, H_{\mathrm{PAR}}\right.$, and $\left.H_{\mathrm{IR}}\right)$ are shown in Figure 13.

Finally, in order to evaluate the variation of solar radiation components, we calculated, for each solar component, the monthly averages of the daily values (Table 9) and the minimum (Table 10) and maximum (Table 11) daily values for each month of the representative year. Caused by the large number of stations, only the results obtained in Rabat's station are presented in Tables 9-11 (minimum, maximum, and averages of the daily values for each month of the representative year).

\section{Discussion}

From the obtained results in Tables 6 and 7 and the curves in Figures 1-3, we can conclude that the correlation between the estimated and measured solar energy resources has a good level of precision. This was reflected in the following observations:

(i) The annual average of daily relative errors for energetic components of solar radiation does not exceed $5.42 \%$ for global radiation, $-3.63 \%$ for diffuse radiation, and $2.32 \%$ for direct radiation

(ii) The comparative curves show that the measured and estimated values of solar radiation undergo almost the same variations throughout the year and the differences that do not exceed $12.14 \%$ for global 


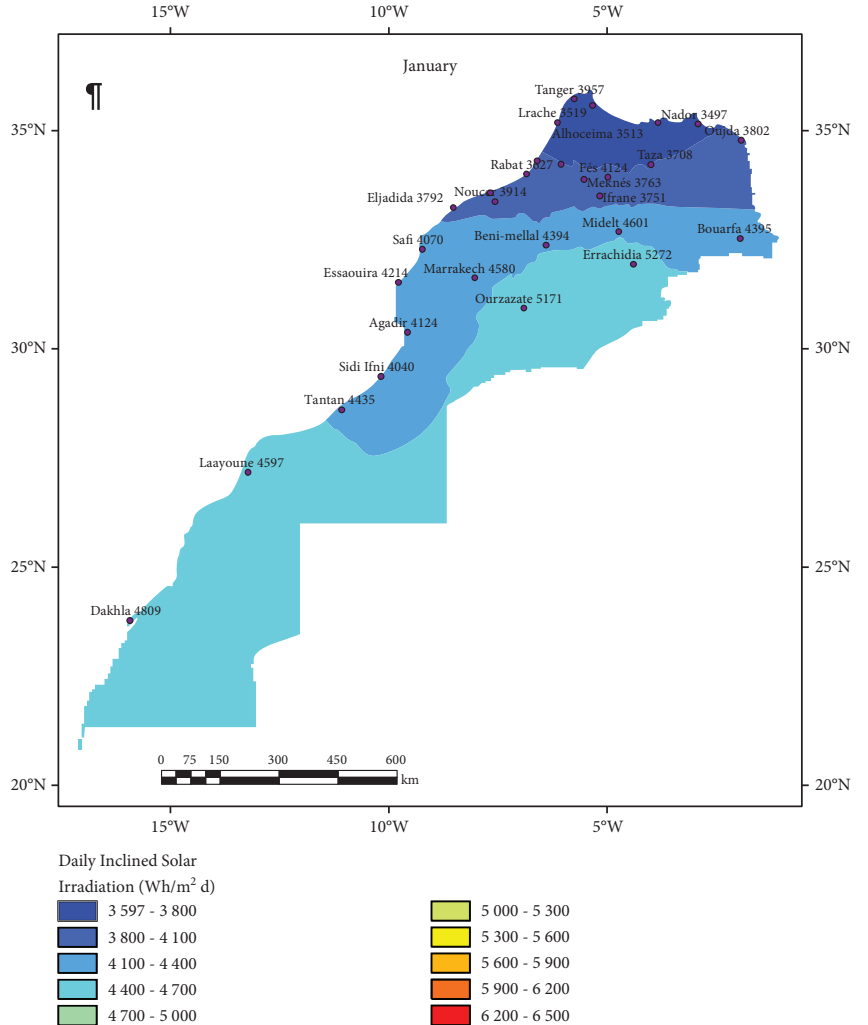

(a)

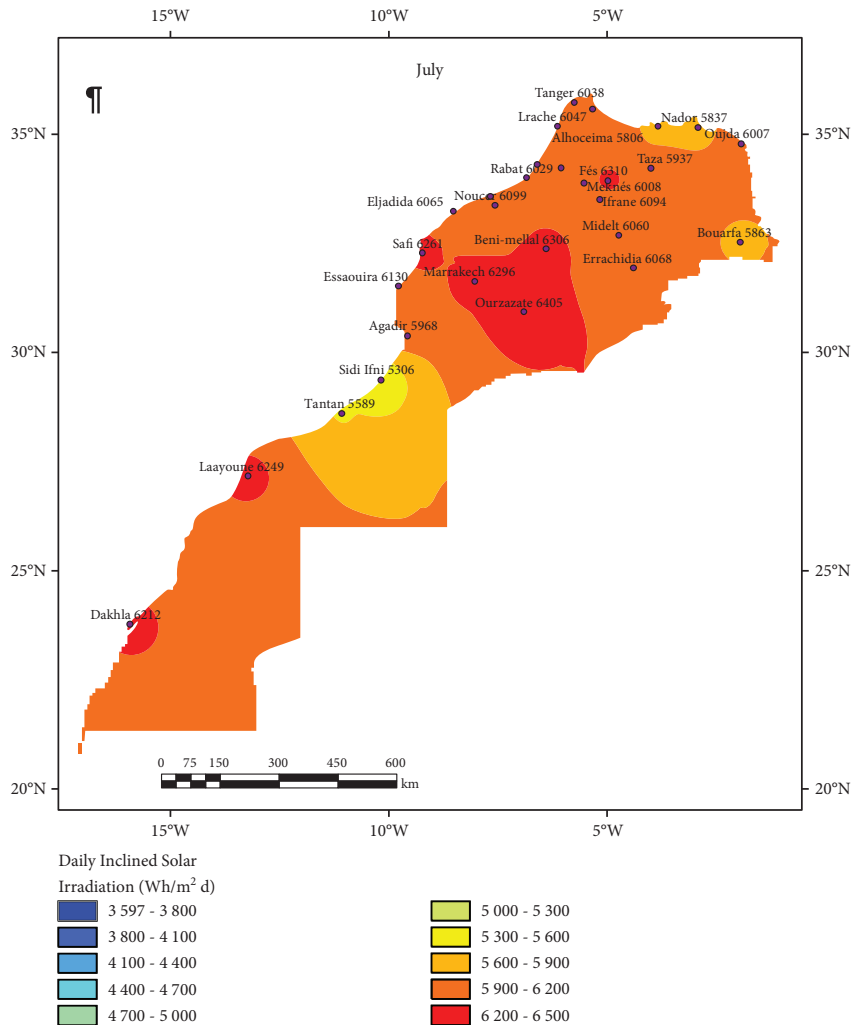

(c)

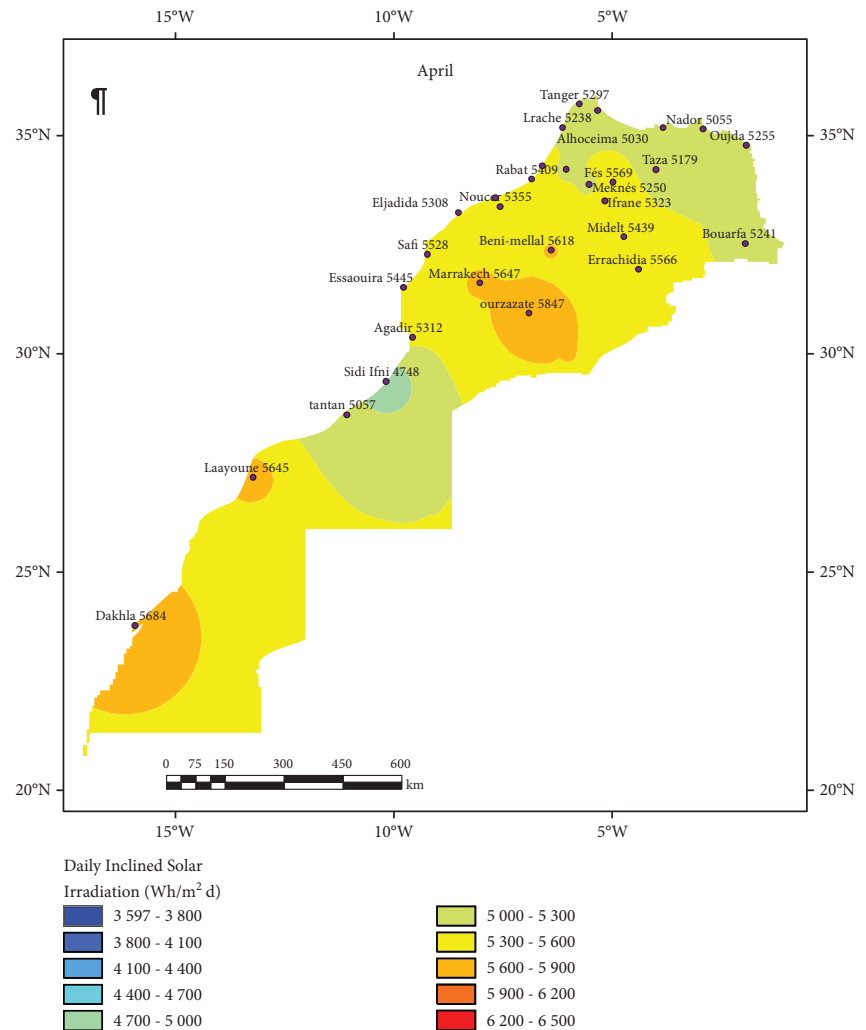

(b)



(d)

FIGURE 11: Maps of the monthly average values of the daily global irradiations on inclined planes $(\beta=$ the site latitude). Maps of the global solar radiation inclined with $\beta=$ the latitude's site $(a-d)$. 


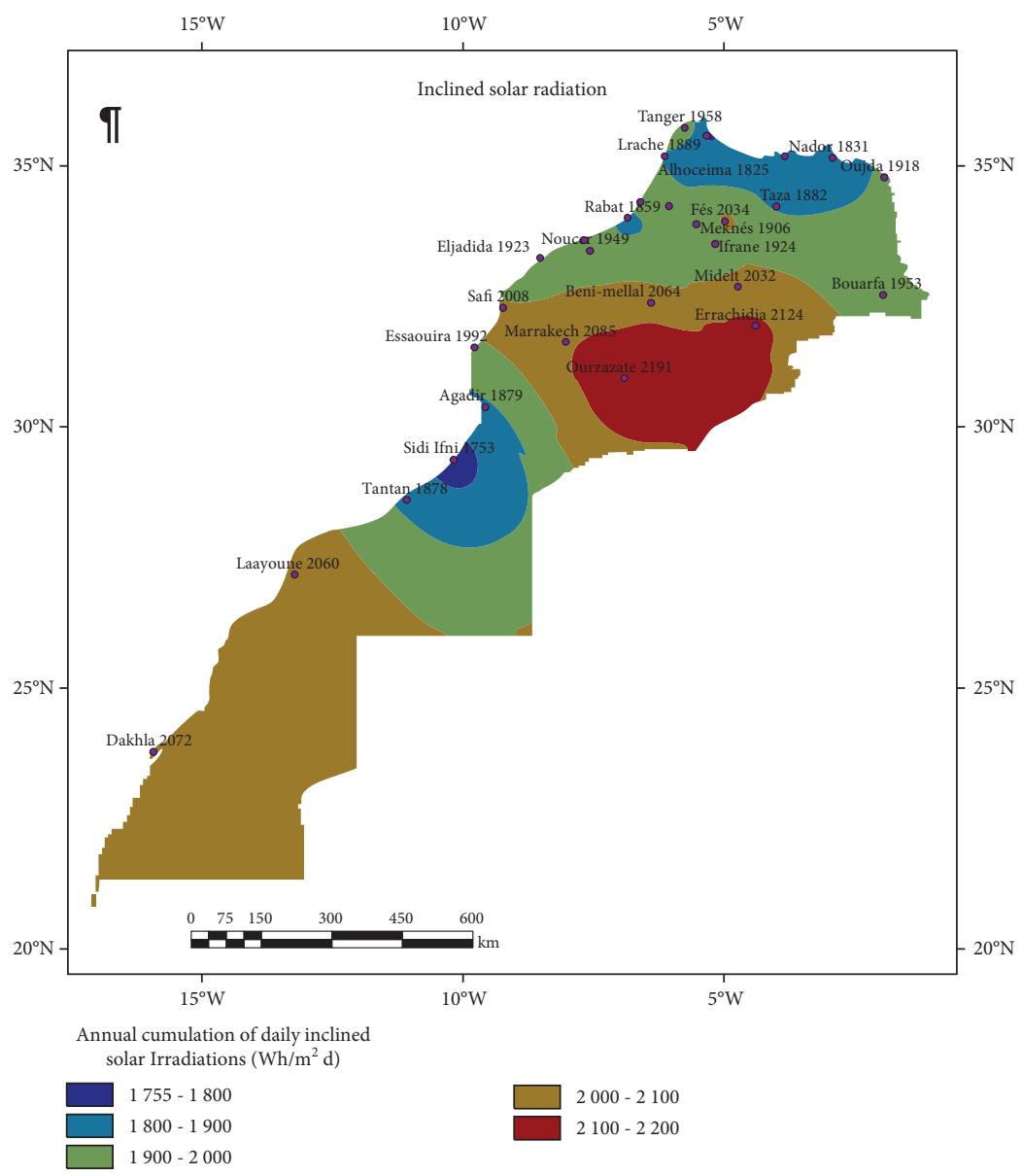

FIGURE 12: Map of annual cumulation of daily global irradiations on inclined planes ( $\beta=$ the site latitude) incident in the Moroccan territory. Map of the global solar radiation inclined with $\beta=$ thelatitude's site.

radiation, $12.71 \%$ for diffuse radiation, and $17 \%$ for direct radiation. This result is approved by comparing the cloud of points generated by representing the estimated values in function of the measured values, with the first bisector, which gave almost identical trends

(iii) For the spectral components, the relative errors do not exceed $3.8 \%$ for $H_{\mathrm{UVT}}, 2.4 \%$ for $H_{\mathrm{PAR}}$, and $2.2 \%$ for $H_{\mathrm{IR}}$

When we compared our results with those obtained by other authors' models, we noticed that our method diminished the differences between estimated and measured values. In brief, the results of this comparison are shown in Table 12.

Regarding the maps in Figures 5-12, we notice that the Moroccan territory receives a very important sunshine during all seasons. However, there is an unequal distribution of solar resources between regions. This inequality is reflected by maximum values of radiation in the south and southeast regions such as Ouarzazate, Er-Rachidia, Laayoun, and Dakhla and by minimum values of solar radiation in the north regions such as Tangier, Tetouan, and the coastal zone between Agadir and Tan-Tan where there is a microclimate.
In addition, the spectral component maps show a similar distribution compared to the global radiation maps, reflected by intense irradiations in the south and south-east regions and low radiations in the north and the microclimate zone. The linear aspect of the estimation equations connecting the spectral components to the global radiation explains this result.

\section{Conclusion}

Through this work, we have been able to create a database that brings together the different components of solar radiation at daily scale over a period of ten years from 2009 to 2018. This database regroups more than one million daily values (1,058,500 values), which divides into 36,500 values for each site.

To create this databank, at first, we developed a model to estimate the different components of the solar radiation, and then we validated this model by comparing the estimated values with the measurements provided by installed stations. As a result, the validity tests showed that our model presents minimal errors that do not exceed $5.42 \%$ for global radiation, $3.8 \%$ for $H_{\mathrm{UVT}}, 2.4 \%$ for $H_{\mathrm{PAR}}$, and $2.2 \%$ for $H_{\mathrm{IR}}$. In addition, we compared our results with those obtained by other 


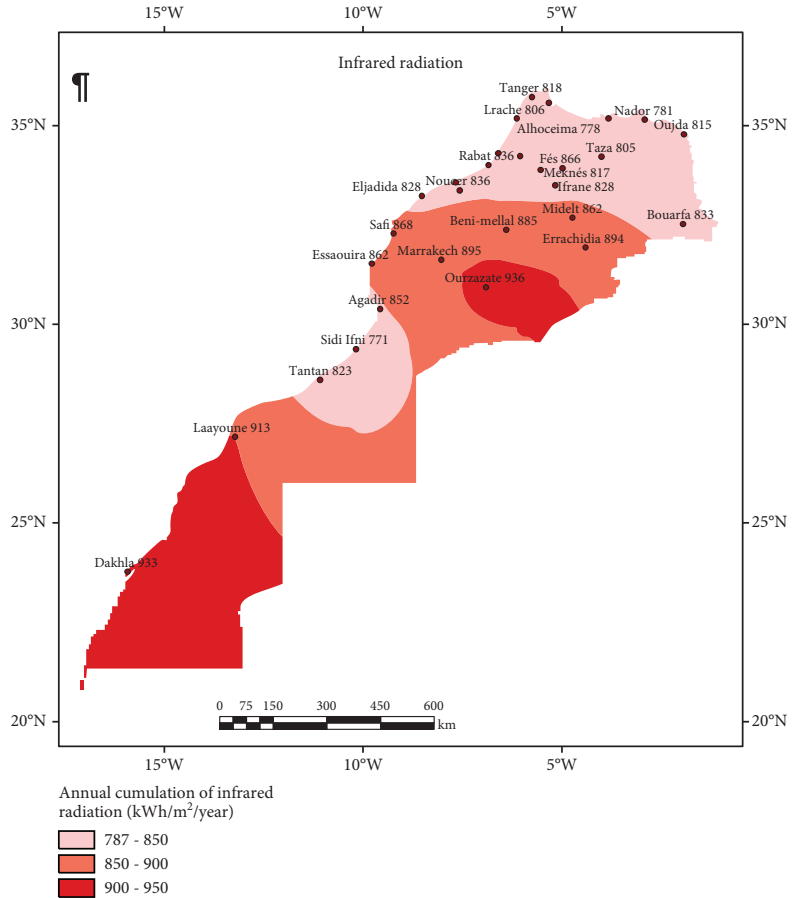

(a)

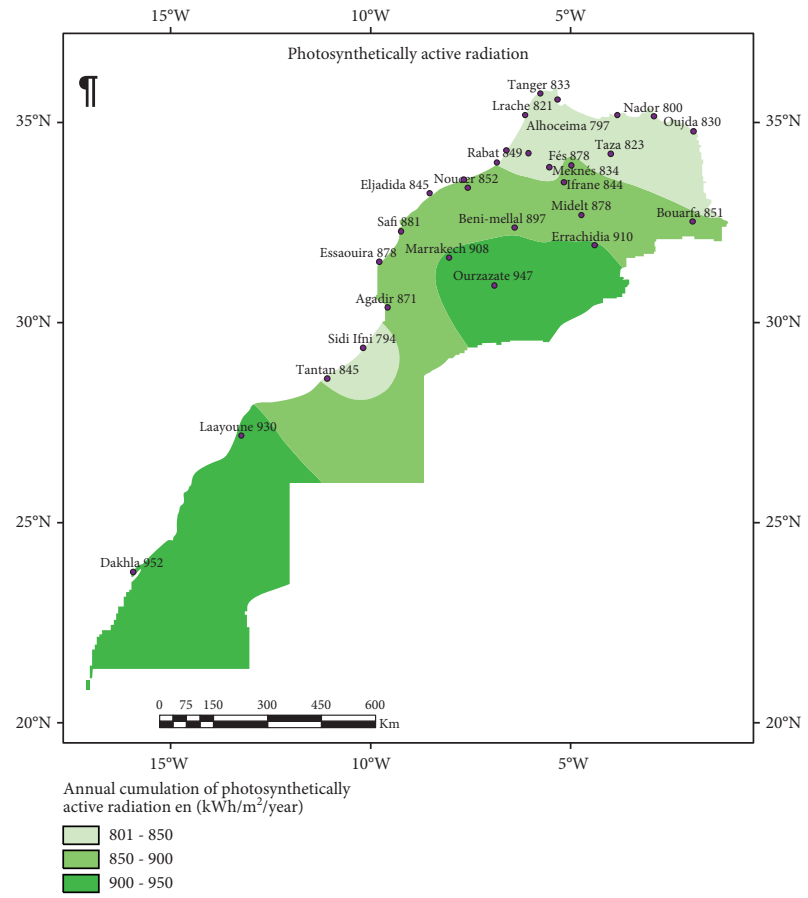

(b)

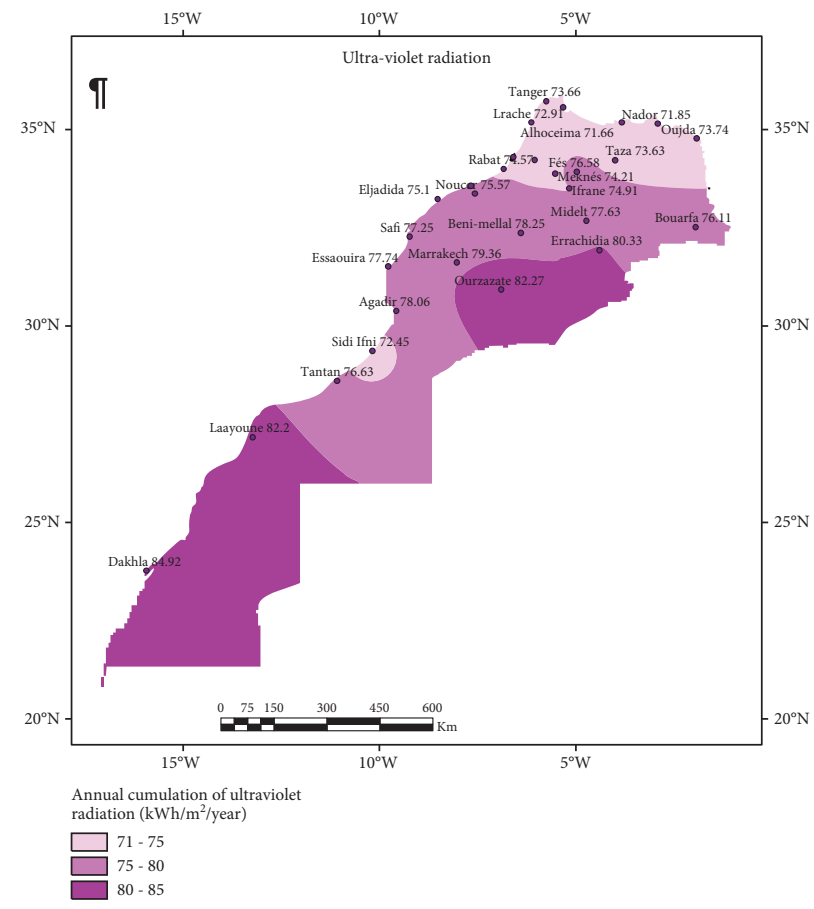

(c)

FIGURE 13: Maps of the annual cumulation of daily irradiations of the spectral components of solar radiation $\left(H_{\mathrm{UVT}}, H_{\mathrm{PAR}}\right.$, and $\left.H_{\mathrm{IR}}\right)$ on the horizontal plane incident in the Moroccan territory. Maps of solar radiation spectral components (a-c).

estimation models developed around the world. The results of this comparison showed the advantage to our model with errors do not exceed $6 \%$.

To get the general idea about the solar radiation distribution over all Morocco and considering the large number of data, we chose to present the obtained results in maps. In order to reduce the number of figures, we chose to represent only the monthly averages of the daily values of the midseason month for the representative year and the annual cumulative solar irradiations for the same year. As a result, twenty-three maps of solar radiation were generated. Consequently, we have been able to complete and to update the various works affected in our laboratory, and we have been able to build a complete, clean, and precise 
TABLE 9: Representative year monthly averages of various solar radiation component daily values $\left(\mathrm{Wh} / \mathrm{m}^{2}\right)$.

\begin{tabular}{|c|c|c|c|c|c|c|c|c|c|c|}
\hline & $H_{j}$ & $H_{d j}$ & $H_{b j}$ & $H_{\beta j}(\beta=\phi+20)$ & $H_{\beta j}(\beta=\phi-20)$ & $H_{\beta j}(\beta=\phi)$ & $H_{\beta j}(\beta=90)$ & $H_{\text {UVT }}$ & $H_{\mathrm{PAR}}$ & $H_{\text {IR }}$ \\
\hline Jan & 2552 & 1302 & 1250 & 3772 & 3072 & 3627 & 3252 & 112 & 1235 & 1200 \\
\hline Feb & 3881 & 1471 & 2409 & 5271 & 4556 & 5223 & 4247 & 162 & 1864 & 1843 \\
\hline Mar & 4493 & 1966 & 2527 & 4718 & 4848 & 5075 & 3273 & 189 & 2162 & 2131 \\
\hline Apr & 5382 & 2401 & 2981 & 4704 & 5511 & 5409 & 2822 & 231 & 2595 & 2542 \\
\hline May & 5859 & 2825 & 3035 & 4489 & 5777 & 5414 & 2491 & 251 & 2825 & 2769 \\
\hline June & 6942 & 2723 & 4220 & 4900 & 6722 & 6129 & 2459 & 299 & 3390 & 3334 \\
\hline Jul & 6668 & 2727 & 3941 & 4900 & 6522 & 6029 & 2546 & 293 & 3312 & 3255 \\
\hline Aug & 5742 & 2552 & 3191 & 4743 & 5788 & 5571 & 2723 & 273 & 3077 & 3020 \\
\hline Sept & 5001 & 1878 & 3124 & 5051 & 5349 & 5526 & 3327 & 227 & 2655 & 2638 \\
\hline Oct & 4231 & 1383 & 2848 & 5533 & 4913 & 5559 & 4313 & 177 & 2076 & 2064 \\
\hline Nov & 2585 & 1196 & 1503 & 3820 & 3117 & 3681 & 3264 & 116 & 1312 & 1290 \\
\hline Dec & 2470 & 1024 & 1508 & 4129 & 3128 & 3855 & 3682 & 119 & 1374 & 1358 \\
\hline
\end{tabular}

TABLE 10: Representative year monthly maximum values.

\begin{tabular}{lcccccccccc}
\hline & $H_{j}$ & $H_{d j}$ & $H_{b j}$ & $H_{\beta j}(\beta=\phi+20)$ & $H_{\beta j}(\beta=\phi-20)$ & $H_{\beta j}(\beta=\phi)$ & $H_{\beta j}(\beta=90)$ & $H_{\mathrm{UVT}}$ & $H_{\mathrm{PAR}}$ & $H_{\mathrm{IR}}$ \\
\hline Jan & 3322 & 1635 & 2211 & 5618 & 4191 & 5206 & 5023 & 146 & 1608 & 1565 \\
Feb & 5050 & 2044 & 3759 & 6730 & 5919 & 6743 & 5481 & 206 & 2414 & 2414 \\
Mar & 6463 & 2786 & 4797 & 6837 & 6940 & 7249 & 5021 & 259 & 3090 & 3090 \\
Apr & 7253 & 3273 & 5212 & 6370 & 7360 & 7257 & 3695 & 298 & 3467 & 3467 \\
May & 8140 & 3570 & 6084 & 5837 & 7962 & 7312 & 2922 & 326 & 3891 & 3891 \\
June & 8192 & 3575 & 5999 & 5556 & 7895 & 7115 & 2684 & 338 & 3916 & 3916 \\
Jul & 7832 & 3652 & 5563 & 5522 & 7612 & 6944 & 2887 & 337 & 3833 & 3833 \\
Aug & 7072 & 3320 & 4551 & 5452 & 7018 & 6600 & 3069 & 312 & 3683 & 3683 \\
Sept & 5883 & 2981 & 4175 & 6065 & 6185 & 6416 & 4235 & 276 & 3303 & 3303 \\
Oct & 5285 & 2424 & 3907 & 6523 & 6034 & 6688 & 5344 & 224 & 2659 & 2659 \\
Nov & 3688 & 1843 & 2669 & 5953 & 4630 & 5638 & 5109 & 163 & 1946 & 1946 \\
Dec & 3061 & 1459 & 2151 & 5530 & 4016 & 5083 & 4984 & 139 & 1583 & 1583 \\
\hline
\end{tabular}

TABLE 11: Representative year monthly minimum values.

\begin{tabular}{|c|c|c|c|c|c|c|c|c|c|c|}
\hline & $H_{j}$ & $H_{d j}$ & $H_{b j}$ & $H_{\beta j}(\beta=\phi+20)$ & $H_{\beta j}(\beta=\phi-20)$ & $H_{\beta j}(\beta=\phi)$ & $H_{\beta j}(\beta=90)$ & $H_{\mathrm{UVT}}$ & $H_{\mathrm{PAR}}$ & $H_{\text {IR }}$ \\
\hline Jan & 1176 & 1011 & 59 & 1051 & 1185 & 1167 & 776 & 56 & 574 & 541 \\
\hline Feb & 1884 & 1074 & 179 & 1712 & 1911 & 1893 & 1258 & 90 & 919 & 867 \\
\hline Mar & 1114 & 1103 & 11 & 936 & 1103 & 1061 & 672 & 54 & 544 & 512 \\
\hline Apr & 886 & 877 & 9 & 741 & 876 & 842 & 531 & 43 & 432 & 407 \\
\hline may & 1843 & 1825 & 18 & 1536 & 1821 & 1747 & 1099 & 89 & 900 & 848 \\
\hline June & 3303 & 2193 & 316 & 2693 & 3254 & 3101 & 1856 & 159 & 1612 & 1519 \\
\hline Jul & 4885 & 2052 & 2109 & 3620 & 4758 & 4403 & 2039 & 138 & 1407 & 1327 \\
\hline Aug & 3996 & 1815 & 833 & 3346 & 3986 & 3840 & 2201 & 173 & 1904 & 1853 \\
\hline Sept & 2418 & 1563 & 171 & 2265 & 2494 & 2502 & 1592 & 89 & 900 & 848 \\
\hline Oct & 2778 & 801 & 823 & 3052 & 3003 & 3189 & 2371 & 39 & 395 & 372 \\
\hline Nov & 931 & 397 & 315 & 734 & 1049 & 1003 & 411 & 19 & 196 & 184 \\
\hline Dec & 679 & 616 & 1 & 659 & 702 & 712 & 359 & 30 & 304 & 286 \\
\hline
\end{tabular}


TABLE 12: Relative errors (RMBE) calculated from the values generated by different methods of estimation and the measured values.

\begin{tabular}{|c|c|c|c|c|c|c|c|}
\hline Solar components & $\begin{array}{c}\text { Our estimation } \\
\text { methods }\end{array}$ & $\begin{array}{l}\text { Nfaoui's } \\
\text { methods }\end{array}$ & $\begin{array}{l}\text { Lemmini's } \\
\text { methods }\end{array}$ & $\begin{array}{l}\text { Bargach's } \\
\text { methods }\end{array}$ & $\begin{array}{c}\text { Benkaddour's } \\
\text { methods }\end{array}$ & $\begin{array}{c}\text { Zou et al.'s } \\
\text { model }\end{array}$ & $\begin{array}{c}\text { Wang et al.'s } \\
\text { model }\end{array}$ \\
\hline Global solar radiation & $5.42 \%$ & $-11 \%$ & $-14.7 \%$ & $-10.6 \%$ & $14.13 \%$ & $-17 \%$ & \\
\hline Diffuse solar radiation & $-3.63 \%$ & $12.76 \%$ & & & $-8 \%$ & & $11.7 \%$ \\
\hline
\end{tabular}

database covering all Morocco over a period of ten years. This database covers the basic needs of engineers, installers of solar systems, and especially researchers who often need a long-term database.

\section{Nomenclature}

$H_{j}$ : Daily global solar radiation on horizontal surface (Wh/m² day)

$H_{d j}$ : Daily diffuse solar radiation $\left(\mathrm{Wh} / \mathrm{m}^{2}\right.$ day)

$H_{\beta j}$ : Daily global solar radiation on tilted surface (Wh/m² day)

$H_{b j}$ : Daily beam solar radiation (Wh/m $\mathrm{m}^{2}$ day)

$H_{f}$ : Daily global solar radiation of Fez's site $\left(\mathrm{Wh} / \mathrm{m}^{2}\right.$ day)

$H_{\text {UVT }}$ : Daily ultraviolet solar radiation (Wh/m $\mathrm{m}^{2}$ day)

$H_{\text {PAR }}$ : Daily photosynthetically active radiation $\left(\mathrm{Wh} / \mathrm{m}^{2}\right.$ day)

$H_{\mathrm{IR}}$ : Daily infrared solar radiation $\left(\mathrm{Wh} / \mathrm{m}^{2}\right.$ day)

$H_{0}$ : Daily extraterrestrial solar irradiation $\left(\mathrm{Wh} / \mathrm{m}^{2}\right.$ day)

$I_{0}$ : $\quad$ Solar constant $1367 \mathrm{~W} / \mathrm{m}^{2}$

$\varphi$ : $\quad$ Latitude of the place $\left({ }^{\circ}\right)$

$\delta: \quad$ Solar declination $\left({ }^{\circ}\right)$

$R^{2}$ : $\quad$ Correlation coefficient (\%)

RMBE: Relative error (\%)

MAE: Mean absolute error (\%)

MAPE: The mean absolute error percentage (\%)

RMSE: The mean squared error (\%)

$K_{t}: \quad$ Daily clearness index

$K_{d}: \quad$ Daily diffuse fraction

$\sigma: \quad$ Insolation fraction.

\section{Data Availability}

The data used to support the findings of this study are available from the corresponding author upon request.

\section{Conflicts of Interest}

The authors declare that there is no conflict of interest regarding the publication of this paper.

\section{Acknowledgments}

This work was supported by the Arab Fund for Economic and Social Development (AFESD) and Mohammed V University as part of the 2012 emergency plan.

\section{References}

[1] J. Fan, L. Wu, F. Zhang et al., "Empirical and machine learning models for predicting daily global solar radiation from sunshine duration: a review and case study in China," Renewable and Sustainable Energy Reviews, vol. 100, pp. 186-212, 2019.

[2] L. Feng, A. Lin, L. Wang, W. Qin, and W. Gong, "Evaluation of sunshine-based models for predicting diffuse solar radiation in China," Renewable and Sustainable Energy Reviews, vol. 94, pp. 168-182, 2018.

[3] L. Zou, L. Wang, L. Xia, A. Lin, B. Hu, and H. Zhu, "Prediction and comparison of solar radiation using improved empirical models and adaptive neuro-fuzzy inference systems," Renewable Energy, vol. 106, pp. 343-353, 2017.

[4] N. S. Chukwujindu, "A comprehensive review of empirical models for estimating global solar radiation in Africa," Renewable and Sustainable Energy Reviews, vol. 78, pp. 955-995, 2017.

[5] M. Abdel Wahab and K. S. M. Essa, "Extrapolation of solar irradiation measurements: case study over Egypt," Renewable Energy, vol. 14, no. 1-4, pp. 229-239, 1998.

[6] O. Nait Mensour, S. Bouaddi, B. Abnay, B. Hlimi, and A. Ihlal, "Mapping and estimation of monthly global solar irradiation in different zones in Souss-Massa area, Morocco, using Artificial Neural Networks," International Journal of Photoenergy, vol. 2017, Article ID 8547437, 19 pages, 2017.

[7] L. Zou, A. Lin, L. Wang et al., "Long-term variations of estimated global solar radiation and the influencing factors in Hunan province, China during 1980-2013," Meteorology and Atmospheric Physics, vol. 128, no. 2, pp. 155-165, 2016.

[8] W. Qin, L. Wang, A. Lin et al., "Comparison of deterministic and data-driven models for solar radiation estimation in China," Renewable and Sustainable Energy Reviews, vol. 81, pp. 579-594, 2018.

[9] L. Wang, O. Kisi, M. Zounemat-Kermani et al., "Prediction of solar radiation in China using different adaptive neuro-fuzzy methods and M5 model tree," International Journal of Climatology, vol. 37, no. 3, pp. 1141-1155, 2017.

[10] J. E. Hay, "Satellite based estimates of solar irradiance at the earth's surface-I. Modelling approaches," Renewable Energy, vol. 3, no. 4-5, pp. 381-393, 1993.

[11] A. Mechaqrane, Contribution à l'étude des images du satellite METEOSAT pour la détermination du gisement solaire marocain, Thèse de 3ème cycle, Faculté des Sciences de Rabat, 1990.

[12] L. E. Akpabio and S. E. Etuk, "Relationship between global solar radiation and sunshine duration for Onne, Nigeria," Turkish Journal of Physics, vol. 27, pp. 161-167, 2003.

[13] E. O. Ogolo, "Estimation of global solar radiation in Nigeria using a modified angstrom model and the trend analysis of the allied meteorological components," Indian Journal of Radio \& Space Physique, vol. 43, pp. 213-324, 2014.

[14] L. Wang, O. Kisi, M. Zounemat-Kermani, G. A. Salazar, Z. Zhu, and W. Gong, "Solar radiation prediction using different techniques: model evaluation and comparison," Renewable and Sustainable Energy Reviews, vol. 61, pp. 384-397, 2016.

[15] C. M. Dos Santos, J. L. De Souza, R. A. Ferreira Junior et al., "On modeling global solar irradiation using air temperature 
for Alagoas State, Northeastern Brazil," Energy, vol. 71, pp. 388-398, 2014.

[16] F. Oloo, L. Olang, and J. Strobl, "Spatial modelling of solar energy potential in Kenya," International Journal of Sustainable Energy and Management, vol. 6, pp. 17-30, 2016.

[17] M. R. Yaïche and S. M. A. Bekkouche, "Estimation du rayonnement solaire global en Algérie pour différents types de ciel," Revue des Energies Renouvelables, vol. 13, pp. 683-695, 2010.

[18] M. Koussa, M. Haddadi, and A. MALEK, "Reconstitution des irradiations globale et diffuse en fonction de quelques paramètres météorologiques pour un ciel quelconque," Revue des Energies Renouvelables, vol. 10, pp. 75-92, 2007.

[19] T. E. Boukelia, M. S. Mecibah, and I. E. Meriche, "General models for estimation of the monthly mean daily diffuse solar radiation (case study: Algeria)," Energy Conversion and Management, vol. 81, pp. 211-219, 2014.

[20] J. C. Lam and D. H. W. Li, "correlation between global solar radiation and its direct and diffuse components," Building and Environment, vol. 31, no. 6, pp. 527-535, 1996.

[21] B. Jamil and A. T. Siddiqui, "Generalized models for estimation of diffuse solar radiation based on clearness index and sunshine duration in India: applicability under different climatic zones," Journal of Atmospheric and Solar-Terrestrial Physics, vol. 157-158, pp. 16-34, 2017.

[22] F. Cao, H. Li, T. Yang, Y. Li, T. Zhu, and L. Zhao, "Evaluation of diffuse solar radiation models in Northern China: new model establishment and radiation sources comparison," Renewable Energy, vol. 103, pp. 708-720, 2017.

[23] H. D. Kambezidis, B. E. Psiloglou, D. Karagiannis, U. C. Dumka, and D. G. Kaskaoutis, "Recent improvements of the meteorological radiation model for solar irradiance estimates under all-sky conditions," Renewable Energy, vol. 93, pp. 142-158, 2016.

[24] C. Renno, F. Petito, and A. Gatto, "ANN model for predicting the direct normal irradiance and the global radiation for a solar application to a residential building," Journal of Cleaner Production, vol. 135, pp. 1298-1316, 2016.

[25] L. Wang, Y. Lu, L. Zou et al., "Prediction of diffuse solar radiation based on multiple variables in China," Renewable and Sustainable Energy Reviews, vol. 103, pp. 151-216, 2019.

[26] A. A. El-Sebaii, F. S. Al-Hazmi, A. A. Al-Ghamdi, and S. J. Yaghmour, "Global, direct and diffuse solar radiation on horizontal and tilted surfaces in Jeddah, Saudi Arabia," Applied Energy, vol. 87, no. 2, pp. 568-576, 2010.

[27] A. Ibrahim, A. A. El-sebaii, M. R. I. Ramadan, and S. M. El-broullesy, "Estimation of solar irradiance on inclined surfaces facing south in Tanta, Egypt," International Journal of Renewable Energy Research, vol. 1, pp. 18-25, 2011.

[28] L. Feng, W. Qin, L. Wang, A. Lin, and M. Zhang, "Comparison of artificial intelligence and physical models for forecasting photosynthetically active radiation," Remote Sensing, vol. 10, no. 11, p. 1855, 2018.

[29] L. Wang, O. Kisi, M. Zounemat-Kermani, B. Hu, and W. Gong, "Modeling and comparison of hourly Photosynthetically Active Radiation in different ecosystems," Renewable and Sustainable Energy Reviews, vol. 56, pp. 436-453, 2016.

[30] Z. IHSANE, Contribution à l'étude du gisement solaire Marocain: Irradiations journalières et horaires, globale, diffuse, et direct, d'un plan horizontal, Thèse de 3ème cycle. Faculté des sciences de Rabat, 1989.
[31] M. N. Bargach, Contribution à l'étude du gisement solaire marocain. Application à un générateur photovoltaïque, Thèse de 3ème cycle, Faculté des sciences de Rabat, 1983.

[32] F. Lemmini, Etude du rayonnement Global à Beni-Mellal. Rapport interne, Laboratoire d'énergie solaire Rabat, 1983.

[33] H. Nfaoui, "Trois années de mesures d'ensoleillement à Rabat. Etude statistique et présentations des données," Thèse de 3ème cycle. Faculté des Sciences de Rabat, 1986.

[34] M. L. Ben Kaddour, Etude du gisement solaire au Maroc en vue de son exploitation dans l'habitat, Travail de fin d'etudes,Ecole Nationale des travaux publics de l'Etat, vaulx-en-velin, France, 1981.

[35] B. Pillot, M. Muselli, P. Poggi, and J. B. Dias, "Satellite-based assessment and in situ validation of solar irradiation maps in the Republic of Djibouti," Solar Energy, vol. 120, pp. 603619, 2015.

[36] P. Blanc, Atlas du potentiel solaire photovoltaïque et thermodynamique en région $\mathrm{Paca}$, Centre Energétique et Procédés MINES Paris Tech/ARMINES, 2011.

[37] R. M. Yaich and A. Bouhanik, Atlas Solaire Algérien, Centre de développement de l'énergie renouvelable, Algérie, 2002.

[38] A. Mefti, M. Y. Bouroubi, and A. Khellaf, "Analyse critique du modèle de l'atlas solaire de l'Algérie," Revue des Energies Renouvelable, vol. 2, pp. 69-85, 1999.

[39] J. Almorox, M. Benito, and C. Hontoria, "Estimation of monthly Angström-Prescott equation coefficients from measured daily data in Toledo, Spain," Renewable Energy, vol. 30, no. 6, pp. 931-936, 2005.

[40] J. Bahraoui-Buret, M. N. Bargach, and M. L. Benkadour, Le gisement solaire marocain. Editions SMER, 1983.

[41] The Eppley Laboratory INC, 12 Sheffield Avenue Newport, RI 02840-1618 USAhttp://www.EppleyLab.com.

[42] B. Ihya, A. Mechaqrane, R. Tadili, and M. N. Bargach, "Prediction of hourly and daily diffuse solar fraction in the city of Fez (Morocco)," Theoretical and Applied Climatology, vol. 120, no. 3-4, pp. 737-749, 2015.

[43] M. T. Joutey, Etude et validité des méthodes d'extrapolation de rayonnement solaire globale. Mémoire de master en physique énergie et technologie des matériaux, Faculté des sciences de Rabat, 2010.

[44] L. BAHMAD, Caractérisation de l'état de l'atmosphère à Rabat : transmission, extinction, trouble atmosphérique, Thèse de 3ème cycle, Faculté des Sciences de Rabat, 1986.

[45] M. Iqbal, An introduction to Solar Radiation, Academic press, Canada, 1983.

[46] A. Khtira, Etude théorique et expérimentale du rayonnement direct à Rabat, Contribution à l'utilisation des images satellite METEOSAT pour la détermination du gisement solaire, Thèse de 3ème cycle. Faculté des sciences de Rabat, 1984.

[47] C. H. Perrin de Brichambaut and C. H. Vauge, Le gisement solaire : évaluation de la ressource énergétique. Technique et Documentation, Lavoisier, 1982.

[48] V. Badescu, Modeling Solar Radiation at the Earth's Surface, Springer-Verlag, Berlin Heidelberg, 2008.

[49] B. Ihya, A. Mechaqrane, R. Tadili, and M. N. Bargach, "Optimal tilt angles for solar collectors facing south at Fez city (Morocco)," Journal of Natural Sciences Research, vol. 4, no. 10, pp. 120-127, 2014.

[50] S. Lahjomri, Etude des rayonnements ultraviolets et infrarouges à Rabat, Mémoire de DESA, Faculté des sciences de Rabat, 2001. 
[51] M. Hamatti, R. Tadili, M. N. Bargach, A. Mechaqrane, and B. Ihya, "Evaluation des composantes spectrales du rayonnement solaire à rabat (MAROC)," Revue Internationale D'Héliotechnique, vol. 44, pp. 1-6, 2012.

[52] J. F. Escobedo, E. N. Gomes, A. P. Oliveira, and J. Soares, "Modeling hourly and daily fractions of UV, PAR and NIR to global solar radiation under various sky conditions at Botucatu, Brazil," Applied Energy, vol. 86, no. 3, pp. 299-309, 2009. 

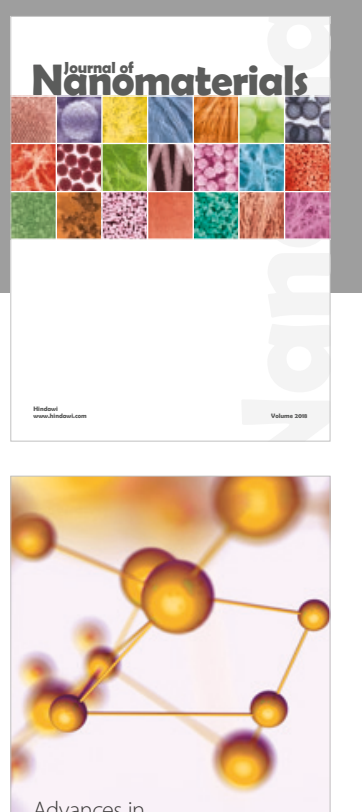

Physical Chemistry
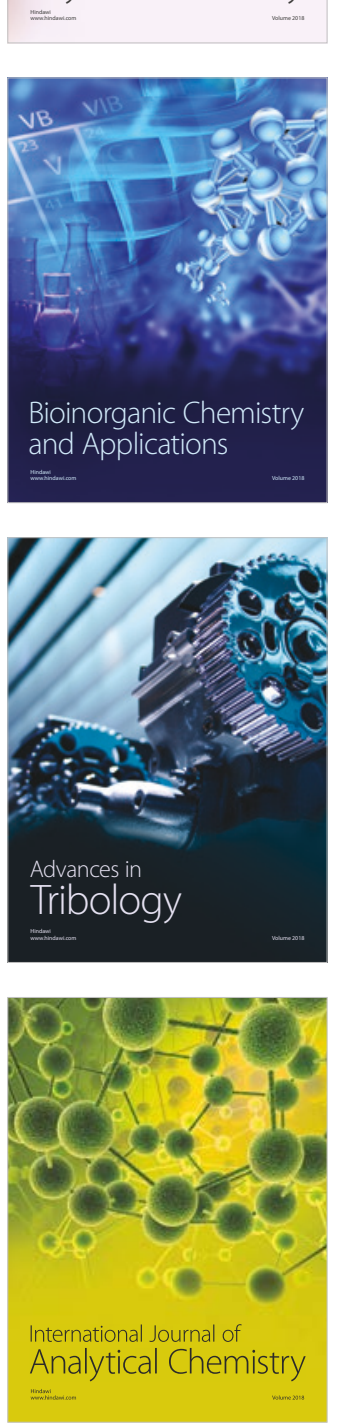

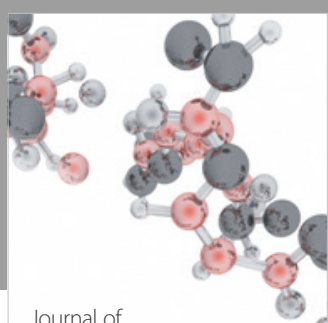

Analytical Methods

in Chemistry



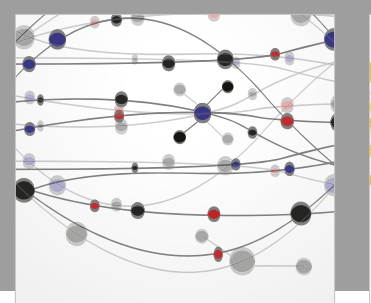

The Scientific World Journal



Journal of

Applied Chemistry
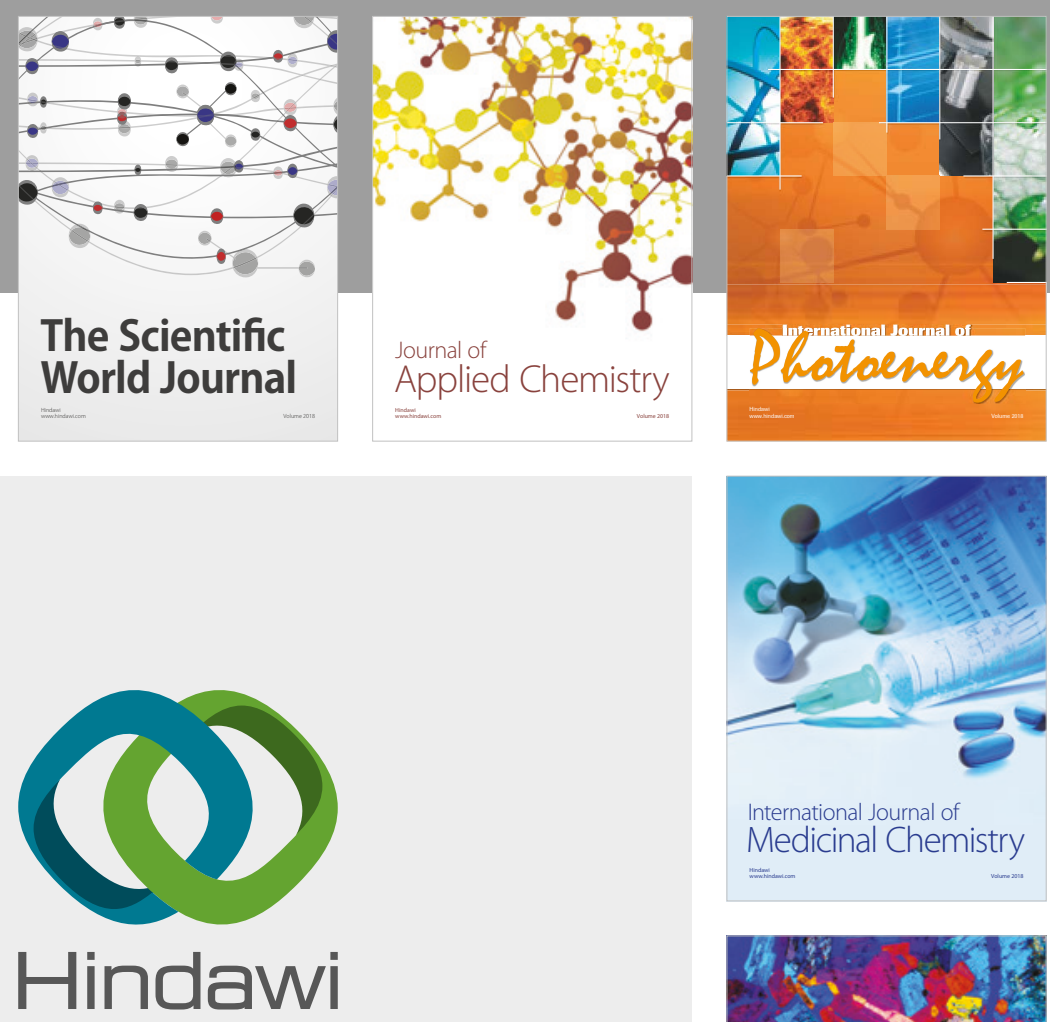

Submit your manuscripts at

www.hindawi.com
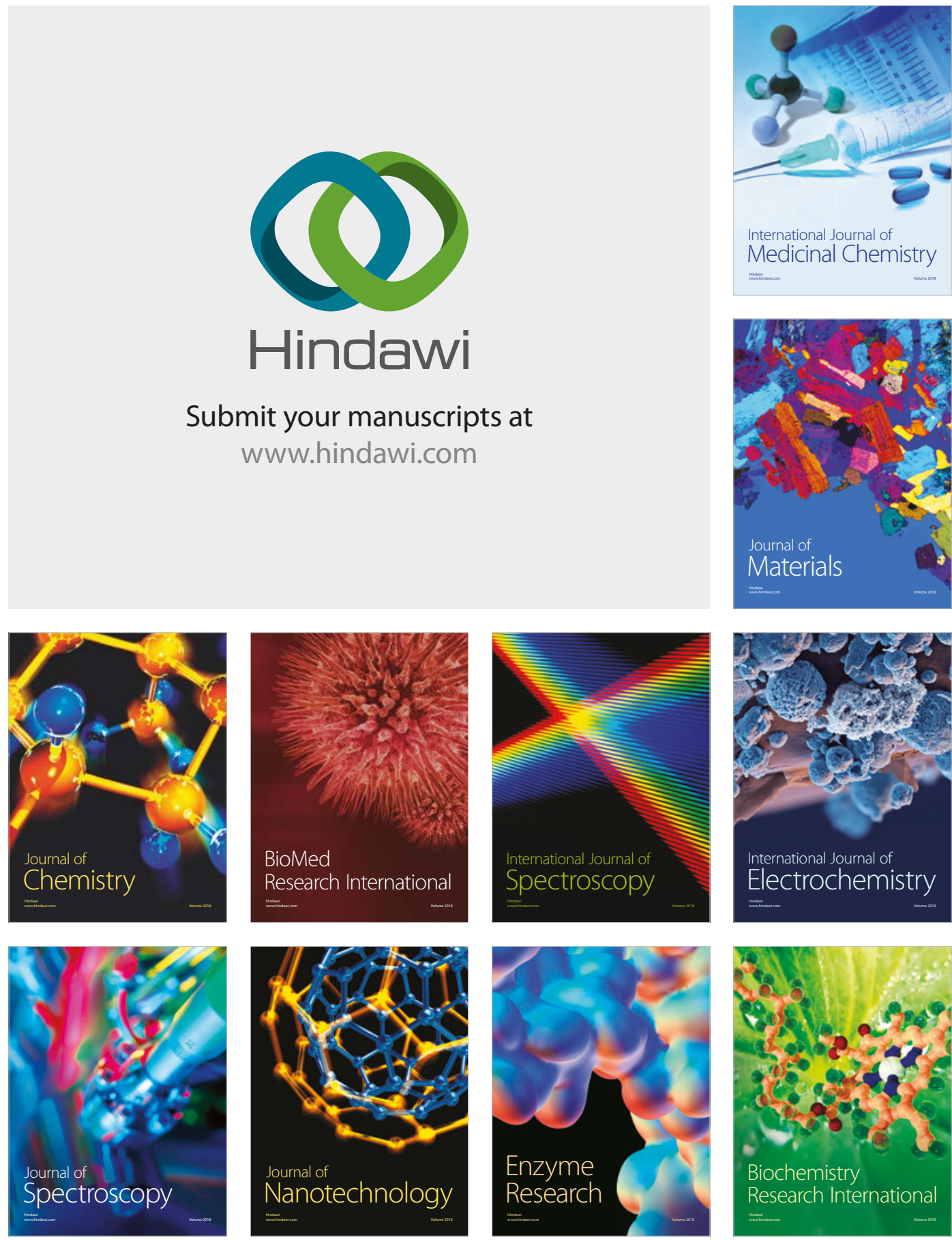
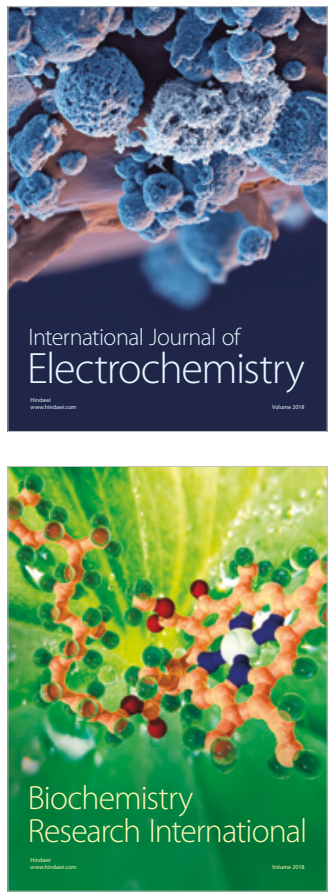